Journal of Geophysical Research: Earth Surface

\section{RESEARCH ARTICLE \\ 10.1002/2017JF004209 \\ Key Points: \\ Atmospheric form drag coefficients over Arctic sea ice using remotely sensed ice topography data, spring 2009-2015}

- Estimated the neutral atmospheric form drag coefficient over western Arctic sea ice using high-resolution IceBridge topography data

- Analyzed the regional and temporal variability of the form drag coefficient and compared with linear profiling estimates

- Produced pan-Arctic estimates of the neutral atmospheric form (and total) drag coefficient utilizing ASCAT satellite radar backscatter data

Supporting Information:

- Supporting Information S1

Correspondence to:

A. A. Petty,

alek.a.petty@nasa.gov

\section{Citation:}

Petty, A. A., M. C. Tsamados, and N. T. Kurtz (2017), Atmospheric form drag coefficients over Arctic sea ice using remotely sensed ice topography data, spring 2009-2015, J. Geophys. Res. Earth Surf., 122, doi:10.1002/2017JF004209.

Received 9 JAN 2017

Accepted 16 JUN 2017

Accepted article online 24 JUN 2017

(2017. American Geophysical Union. All Rights Reserved.

\author{
Alek A. Petty ${ }^{1,2}$ D, Michel C. Tsamados ${ }^{3}$, and Nathan T. Kurtz ${ }^{1}$ \\ ${ }^{1}$ Cryospheric Sciences Laboratory, NASA Goddard Space Flight Center, Greenbelt, Maryland, USA, ${ }^{2}$ Earth System Science \\ Interdisciplinary Center, University of Maryland, College Park, Maryland, USA, ${ }^{3}$ Centre for Polar Observation and \\ Modelling, Department of Earth Sciences, University College London, London, UK
}

Abstract Sea ice topography significantly impacts turbulent energy/momentum exchange, e.g., atmospheric (wind) drag, over Arctic sea ice. Unfortunately, observational estimates of this contribution to atmospheric drag variability are spatially and temporally limited. Here we present new estimates of the neutral atmospheric form drag coefficient over Arctic sea ice in early spring, using high-resolution Airborne Topographic Mapper elevation data from NASA's Operation IceBridge mission. We utilize a new three-dimensional ice topography data set and combine this with an existing parameterization scheme linking surface feature height and spacing to form drag. To be consistent with previous studies investigating form drag, we compare these results with those produced using a new linear profiling topography data set. The form drag coefficient from surface feature variability shows lower values $\left(<0.5-1 \times 10^{-3}\right)$ in the Beaufort/Chukchi Seas, compared with higher values $\left(>0.5-1 \times 10^{-3}\right)$ in the more deformed ice regimes of the Central Arctic (north of Greenland and the Canadian Archipelago), which increase with coastline proximity. The results show moderate interannual variability, including a strong increase in the form drag coefficient from 2013 to 2014/2015 north of the Canadian Archipelago. The form drag coefficient estimates are extrapolated across the Arctic with Advanced Scatterometer satellite radar backscatter data, further highlighting the regional/interannual drag coefficient variability. Finally, we combine the results with existing parameterizations of form drag from floe edges (a function of ice concentration) and skin drag to produce, to our knowledge, the first pan-Arctic estimates of the total neutral atmospheric drag coefficient (in early spring) from 2009 to 2015.

\section{Introduction}

Sea ice is a heterogeneous medium that evolves through a combination of thermodynamic and dynamic processes. The sea ice morphology modulates the turbulent fluxes of momentum (drag) and sensible/latent heat over and under the ice surface [e.g., Arya, 1973]. The atmosphere-ice (wind) drag is the dominant component of the sea ice momentum balance on seasonal time scales and thus controls how sea ice drifts under the influence of wind forcing [e.g., Hibler III, 1979; Thorndike and Colony, 1982; Steele et al., 1997].

The atmosphere-ice drag is parameterized in most climate models using a simple quadratic boundary law

$$
\tau_{\mathbf{a}}=\rho_{a} C_{\text {da }}\left|\mathbf{U}_{\mathbf{a}}\right| \mathbf{U}_{\mathbf{a}}
$$

where $\mathbf{U}_{\mathbf{a}}$ is the near-surface wind velocity (which is assumed to be much larger than the ice velocity) and $C_{d a}$ is a bulk atmospheric drag coefficient [e.g., Brown, 1980]. Note that the atmospheric drag coefficient is often calculated at a reference height of $10 \mathrm{~m}$ to match the lowest (near-surface) height level used in climate models. The atmospheric drag coefficient is strongly modified by the impact of the atmospheric boundary layer stability [Birnbaum and Lupkes, 2002] and is strongly enhanced (reduced) in an unstable (stable) boundary layer where strong (weak) turbulent mixing is present. A constant value of the atmospheric drag coefficient assuming a neutral boundary layer, $C_{\mathrm{da}^{\prime}}^{n}$ is thus often used as an initial estimate before stability effects are taken into consideration. The heat and moisture turbulent exchange coefficients are often set to the same value as the drag coefficient; however, Schröder et al. [2003] found that the heat and moisture exchange coefficients can be as much as $50 \%$ lower than the drag coefficient over unconsolidated ice. 
Neutral atmospheric drag coefficients over sea ice show a variability of roughly half an order of magnitude, based on the analysis of data collected over Arctic (and Antarctic) sea ice over the last several decades [e.g., Overland, 1985; Guest and Davidson, 1991; Lüpkes and Birnbaum, 2005; Andreas et al., 2010; Lüpkes et al., 2012; Andreas et al., 2012; Castellani et al., 2014]. As first discussed by Arya [1973, 1975], the total neutral atmospheric drag coefficient can be decomposed into a contribution from frictional skin drag (due to microscale roughness elements) and form drag that acts on discrete surface obstacles, such as pressure ridges and the edges of ice floes and melt pond, as

$$
C_{\mathrm{da}}^{n}=C_{\mathrm{da}, \mathrm{s}}^{n}+C_{\mathrm{da}, \mathrm{f}}^{n},
$$

where $C_{\mathrm{da}, \mathrm{s}}^{n}$ is the neutral atmospheric skin drag coefficient and $C_{\mathrm{da}, \mathrm{f}}^{n}$ is the neutral atmospheric form drag coefficient. $C_{\mathrm{da}, \mathrm{s}}^{n}$ is often assumed to be constant (although it is thought to be reduced due to a sheltering effect within deformed ice regimes), meaning the variability of $C_{\mathrm{da}}^{n}$ is thought to be driven primarily by variability in $C_{\mathrm{da}, \mathrm{f}}^{n}$

Observational estimates of the atmospheric drag coefficient have been based on data collected predominantly within the Marginal Ice Zone (MIZ) [e.g., Andreas et al., 2010; Elvidge et al., 2016, and references therein]. In the Fram Strait MIZ, the impact on $C_{\text {da,f }}^{n}$ from pressure ridges was shown to be small [Mai et al., 1996] and is instead thought to be driven by variability in ice concentration and the resultant variability in exposed floe edges. In the Central Arctic ice pack, where ice deformation results in a higher density of pressure ridges, the impact on $C_{\mathrm{da}, \mathrm{f}}^{n}$ is thought to be more significant [e.g., Arya, 1973; Garbrecht et al., 2002; Leonardi et al., 2003]. The impact of surface feature variability (e.g., pressure ridges) on $C_{d a, f}^{n}$ has generally been overlooked in observational studies, however, as regions where it is most important (within the consolidated ice pack of the Central Arctic) are the least accessible parts of the Arctic. A recent study by Castellani et al. [2014] (referred to herein as C2014) combined a series of laser altimetry profiling campaigns, which spanned several decades, to estimate the variability in $C_{\mathrm{da}, \mathrm{f}}^{n}$ from ice topography variability over several different regions across the Arctic. They demonstrated a near doubling of $C_{\mathrm{da}}^{n}$ over the more deformed ice north of Greenland $\left(C_{\mathrm{da}}^{n} \approx 2.6 \times 10^{-3}\right.$ in the Lincoln Sea) compared to the less deformed ice of the peripheral Arctic seas (e.g., $C_{\mathrm{da}}^{n} \approx 1.6 \times 10^{-3}$ in the Beaufort Sea).

A general parameterization of form drag was proposed by Lüpkes et al. [2012] and implemented in the sea ice model CICE by Tsamados et al. [2014] (referred to herein as T2014) where the term $C_{\text {da, }}^{n}$ was decomposed into its ridge, floe edge, and melt pond edge components as

$$
C_{\mathrm{da}, \mathrm{f}}^{n}=C_{\mathrm{da}, \mathrm{fr}}^{n}+C_{\mathrm{da}, \mathrm{ff}}^{n}+C_{\mathrm{da}, \mathrm{fp}}^{n} \text {. }
$$

T2014 found that $C_{\text {daf }}^{n}$ varied seasonally by a factor of 2 and regionally (across the Arctic) by a factor of $4 . C_{\text {dafr }}^{n}$ dominated the total form drag in winter, while $C_{\text {da,ff }}$ dominated in summer. In a follow-up study, Tsamados et al. [2015] showed that including the new form drag scheme in CICE caused a significant $(\sim 1 \mathrm{~m})$ decrease in ice thickness within the heavily ridged ice north of Greenland and the Canadian Archipelago due to the increased momentum and heat transfer coefficients and thus increase in surface/basal melt. Martin et al. [2016] recently used this new form drag scheme in CICE to explore the role of variable form drag on the integrated Arctic momentum transfer (due to variability in turbulent fluxes and ice strength) and found that accounting for form drag had the potential to reverse the trend of Arctic basin integrated momentum transfer. Several of the parameters introduced in the T2014 form drag parameterization scheme are unconstrained, however, and a degree of uncertainty remains as to the accuracy of the simulated variability in form drag (see supporting information in T2014). In a coupled global ice-ocean model study by Zhang and Rothrock [2003], the simulated sea ice drift, and resultant sea ice state, depends strongly on the chosen drag coefficient, and much stronger agreement with observations was possible with an optimized drag coefficient (prescribed using a simple relationship with ice type, as proposed by Overland [1985]). Constraining the drag coefficient used in Global Climate Models, especially considering the recent advances in variable drag parameterization schemes, offers the potential to improve our understanding of atmosphere-ice-ocean interactions in the polar regions. Unfortunately, consistent, basin-scale observations of the atmospheric (and oceanic) form drag coefficient over (under) sea ice are currently unavailable.

In the recent study of Petty et al. [2016] (referred to herein as P2016), high-resolution Airborne Topographic Mapper (ATM) elevation data obtained during NASA's Operation IceBridge (OIB) mission were used to 


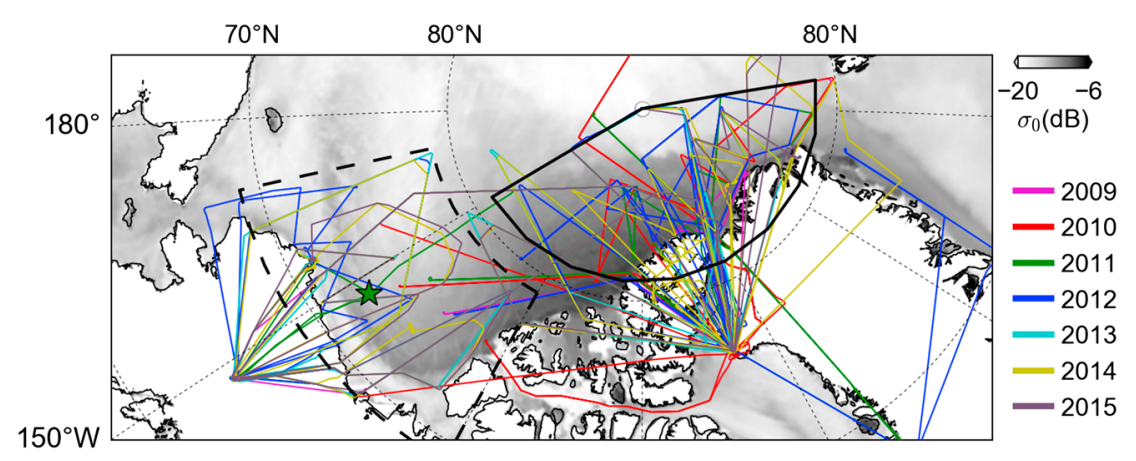

Figure 1. NASA's Operation IceBridge sea ice flight lines from 2009 to 2015 overlaid on the mean ASCAT radar backscatter data $\left(\sigma_{0}\right)$ over all annual IceBridge sea ice campaign periods. The black solid (dashed) lines show the Central Arctic (Beaufort/Chukchi) regions used in this study. The green star indicates the locations of the case study shown in Figures 2 and 5 .

investigate the interannual/regional variability in ice topography over the western Arctic sea ice pack in spring, 2009-2014. In this study we seek to extend the study of P2016 by estimating the contribution of ice topography variability on the neutral atmospheric form drag coefficient from surface feature (e.g., pressure ridge) variability, $C_{\text {da,fr }}^{n}$ over western Arctic sea ice. The data offer an improvement over previous data sets used to investigate ice topography and form drag, e.g., by C2014, due to the combination of high spatial coverage and the use of a conical laser scanner, which provides profiling of the ice surface in three dimensions (the data have a swath width of $\sim 250 \mathrm{~m}$ ). The continuous years of data collection, since 2009 , also increasingly allow for an assessment of interannual variability. To produce the first pan-Arctic estimate of $C_{\mathrm{da}, \mathrm{fr}}^{n}$, we also utilize satellite radar backscatter estimates from the C-band Advanced Scatterometer (ASCAT) to extrapolate the OIB $C_{\text {da,fr }}^{n}$ estimates across the entire Arctic.

The paper is organized as follows: In section 2 we briefly describe the data used in this study; in section 3 we present the neutral atmospheric form drag formulation, including topography/form drag estimates using linear profiling within the ATM swath; in section 4 we present and discuss our results, with conclusions given in section 5 .

\section{Data}

NASA's OIB aircraft carries a suite of instruments designed to profile both land and sea ice. In this study, we primarily make use of the recent sea ice topography data set of P2016, produced using ice surface elevation data obtained by the Airborne Topographic Mapper (ATM). The ATM is a conically scanning laser altimeter operating at $532 \mathrm{~nm}$ and has a swath width of $\sim 250 \mathrm{~m}$ assuming a nominal flight altitude of $\sim 460 \mathrm{~m}$ [Krabill, 2013]. OIB sea ice surveys conducted from Fairbanks, Alaska, provide data over the predominantly first-year ice of the Beaufort/Chukchi Seas, while surveys from Thule, Greenland, sample the thicker/older ice pack of the Central Arctic, north of Greenland, and the Canadian Archipelago. The 2009-2015 OIB spring Arctic sea ice flight lines are shown in Figure 1. A more detailed description of the ATM and ancillary data sets used to produce the Arctic sea ice topography data sets is given in P2016. ATM flight information for the 2009-2014 spring (March/April) sea ice campaigns are given in Table 1 in P2016. The 2015 spring OIB sea ice data cover the range 19 March to 3 April.

The ice topography data sets in P2016 include "bulk" ice topography data, e.g., the mean area and volume of "high" ice topography (ice with a height above the level ice surface over a given threshold, e.g., $20 \mathrm{~cm}$ ) within a given $1 \mathrm{~km}$ section, and data regarding the individual surface features detected, e.g., the height, size, shape, and position of each surface feature, detected using a novel feature picking algorithm. In this study we use the "individual" surface feature data calculated using an elevation threshold of $20 \mathrm{~cm}$. As noted in P2016, we refer to surface features, not pressure ridges, as snow features (e.g., sastrugi and dunes) may also be present in these data. Note that this is the same elevation threshold as used in the study of C2014, although they also explored the contribution from "bigger" features (detected with an elevation threshold of $80 \mathrm{~cm}$ ). We choose to focus solely on the $20 \mathrm{~cm}$ threshold data in this study.

We also produce new estimates of ice topography using a linear profile along the ATM swath edge, to validate against previous linear profiling measurements, as described in the following section. We thus also utilize the 
Level 1 (L1B) ATM elevation data [Krabill, 2013] together with geolocation data from the on board Applanix POS/AV precision orientation system [Dominguez, 2010].

To extrapolate the OIB $C_{\text {dafr }}^{n}$ results across the entire Arctic sea ice cover, we use satellite radar backscatter data from the C-band Advanced Scatterometer (ASCAT). ASCAT currently operates aboard both the MetOp-A and MetOp-B satellites, launched in 2006 and 2012, respectively, by the European Organization for the Exploitation of Meteorological Satellites (EUMETSAT). ASCAT emits pulses in the C-band ( $5.26 \mathrm{GHz}, 5.7 \mathrm{~cm}$ wavelength) with vertical copolarization (VV) and measures the returned radar backscatter $\left(\sigma_{0}\right)$. It has two sets of three fan-beam antennae, measuring incidence angles between $25^{\circ}$ and $65^{\circ}$. In this study we use the enhanced resolution ( $4.5 \mathrm{~km}$ ) Scatterometer Image Reconstruction (SIR) $\sigma_{0}$ data, obtained from the Scatterometer Climate Record Pathfinder (http://www.scp.byu.edu/data/Ascat/SIR/msfa/Arc.html) which are 2 day averages of $\sigma_{0}$, normalized to a $40^{\circ}$ incidence angle [Lindsley and Long, 2016]. For each year, we take the mean of the quasi-daily backscatter data within the dates of the relevant OIB spring sea ice campaign.

While ASCAT, and other scatterometers, primarily measure the backscatter signal of surface waves, radar backscatter has also been used to derive information regarding sea ice type, using information regarding the volume scattering (e.g., brine pockets within the ice) and surface scattering (linked to surface roughness) [e.g., Nghiem et al., 1995; Breivik and Eastwood, 2009; Lindell and Long, 2016]. The EUMETSAT Ocean and Sea Ice Satellite Application Facilities, for example, provide sea ice type estimates using ASCAT data [Aaboe et al., 2015]. At C-band, air pockets in the ice are small relative to its wavelength, and ASCAT is thus less sensitive to volume scattering than lower wavelength scatterometers, e.g., NASA's Ku-band Quick Scatterometer $(2.24 \mathrm{~cm}$ wavelength) and are more sensitive to surface scattering [e.g., Rivas et al., 2012; Mortin et al., 2014; Lindell and Long, 2016].

To mask the extrapolated $C_{\mathrm{da}, \mathrm{fr}}^{n}$ estimates and to briefly explore the form drag coefficient within the Marginal Ice Zone (MIZ), we use the daily NASA Team ice concentration data [Cavalieri et al., 1996] averaged over the relevant OIB sea ice campaign time period. We interpolate these data onto the same $4.5 \mathrm{~km}$ ASCAT/SIR grid.

Following P2016, we also utilize a data set quantifying the distance to the nearest coastline (http://oceancolor. gsfc.nasa.gov/DOCS/DistFromCoast/) to assess $C_{\mathrm{da}, \mathrm{fr}}^{n}$ variability as a function of coastline proximity, and we use the National Snow and Ice Data Center (NSIDC) regional mask of the Arctic Ocean and surrounding regions (http://nsidc.org/data/polar_stereo/tools_masks) to (i) ensure data are over sea ice and (ii) to exclude regions (e.g., the Canadian Archipelago) from some of our analyses.

\section{Methods}

\subsection{Form Drag Parameterization}

As discussed in C2014, different parameterizations of form drag exist in the published literature, including those from Garbrecht et al. [2002], Lüpkes et al. [2012, 2013], and slight variants therein (including the formulation expressed in T2014). The general principles underlying these different formulations are similar and are based on previous studies exploring the momentum flux induced by single objects by Arya [1973, 1975] and Hanssen-Bauer and Gjessing [1988], applied to a sea ice surface containing a random ensemble of "ridges" (surface features) with a given mean height and spacing.

Here we use a similar formulation to the one presented in Garbrecht et al. [2002] (and used in C2014), which is thought to be more appropriate for form drag estimates from surface features over a consolidated ice cover and is given as

$$
C_{\mathrm{da}, \mathrm{fr}}^{n}=\frac{C_{w}}{\pi} \frac{h_{f}}{D_{s}} \frac{\left[\ln \left(h_{f} / z_{0}\right)-1\right]^{2}+1}{\ln \left(h_{\mathrm{ref}} / z_{0}\right)}
$$

where $c_{w}$ the coefficient of resistance of a single ridge/feature and is calculated as a function of the surface feature height, $h_{f}$, following Garbrecht et al. [2002] as $c_{w}=\alpha_{r}+\beta_{r} h_{f}$ where $\alpha_{r}=0.185$ and $\beta_{r}=0.147 \mathrm{~m}^{-1} . D_{s}$ is the surface feature spacing (described later), $z_{0}=1 \times 10^{-5} \mathrm{~m}$ is a surface roughness length scale of level ice, and $h_{\text {ref }}=10 \mathrm{~m}$ is the atmospheric reference height. Note that we have neglected a sheltering function (as used in T2014) as Garbrecht et al. [2002] and C2014 found this had a negligible impact on their estimates of $C_{d a, f r}^{n}$. The surface feature height, $h_{f}$, and spacing, $D_{s}$, are averaged over $10 \mathrm{~km}$ sections following C2014. This was thought to be an appropriate averaging length scale considering typical climate model grid scales 
[Lüpkes et al., 2012], and we found that this represented a reasonable length scale of convergence in our averages of both $h_{f}$ and $D_{s}$ (not shown).

\subsubsection{Feature Height and Spacing Estimates}

C2014 (and other studies estimating $C_{d a, f r}^{n}$ from surface features) use estimates of the feature height and spacing from linear profiling of the ice surface, whereby individual features are detected using the Rayleigh Criterion. Surface features are separated (and classified as unique features) if the trough between them is smaller than half the height of the highest of the two peaks (see Wadhams and Davy [1986] for more details). In P2016, features were detected across the entire ATM swath (full scan), and the heights are thus thought to more likely represent the peaks of surface features, as opposed to the heights calculated using a random crossing along a feature. It is therefore expected that the feature heights in P2016 will be higher than those found in linear profiling (see Lensu [2003] for more details). To explore the potential differences in $C_{\mathrm{da}, \mathrm{ff}}^{n}$ from linear profiling and the P2016 full scan topography data sets, we also produce estimates of ice topography (height and spacing) using the elevation data along the edge of the ATM swath, to simulate a linear profile. We extract the ATM data with an azimuthal angle (angle relative to the plane direction) of $85-95^{\circ}$ (roughly the edge of the swath) and interpolate this on to an equally spaced $(2 \mathrm{~m})$ along-track grid. All peaks above a minimum $(20 \mathrm{~cm}$ ) elevation are found, with the Rayleigh Criterion used to separate "unique" features, as described above. Note that the P2016 level ice surface detection scheme is used to express the elevation points relative to the local level ice surface. Briefly, the level ice surface is found by calculating the minimum elevation gradient across percentile bins (with a bin width of $20 \%$ ).

In linear profiling, the feature spacing is simply the distance between adjacent features along the profile. As discussed in P2016, the feature spacing from the full scan topography data can be estimated using estimates of the ridging density $\sum_{N} L_{f}^{i} / S_{A}$, where $L_{f}^{i}$ is the length of each feature ( $N$ is the total number of features in a section) and $S_{A}$ is the total ice surface area over the given section [Hibler et al., 1972; Arya, 1973]. Assuming a random orientation of features over the given section (10 km), Mock et al. [1972] showed that the mean feature spacing can be calculated as

$$
D_{s}=\frac{\pi}{2} \sum_{i=1}^{N} \frac{S_{A}}{L_{f}^{i}} .
$$

Note that the factor $\pi / 2$ appears in equation (4) based on the same assumption of random feature orientation. The individual feature length, $L_{f}$, can be estimated assuming an elliptically shaped feature as the length of the major axis, given as

$$
L_{f}=\frac{2}{\sqrt{\pi}} \sqrt{S_{f} R},
$$

where $S_{f}$ is the surface area of each feature and $R=\sqrt{C_{p} / C_{s}}$ ) is the degree of elongation of a given feature, calculated using the primary, $C_{p}$, and secondary, $C_{s}$, eigenvalues of the feature covariance matrix C (see P2016 for more details). Note that an elliptically shaped feature was seen to be the most appropriate/flexible shape to use considering the types of feature segments (ridge links) detected by the P2016 processing. We demonstrate graphically the elliptical feature characterization in the following section.

We calculate the feature orientation from the covariance matrix $\mathbf{C}$ and using a chi-square test (not shown) and find that as in Mock et al. [1972], the feature orientations are not truly random. However, as in Mock et al. [1972], we continue with this assumption and the equations above for simplicity. This also allows for easier comparisons with linear profiling results, including those presented in this study, that have invoked this assumption in their estimates of form drag.

It is worth noting that most studies, to date, have utilized linear profiling data regarding feature height and spacing to force the form drag parameterization (and variants of) described above [e.g., Garbrecht et al., 2002; Castellani et al., 2014]. However, the original drag partitioning theory proposed by Arya [1973] assumed two-dimensional ridging density estimates based on the observations of Wittmann and Schule [1966]. It is thus not clear which method is in fact more appropriate, and both likely offer advantages, e.g., feature spacings using linear profiling can arguably be measured more easily/consistently, while the full scan feature spacings based on ridging density may be more representative. We thus present $C_{d a, f r}^{n}$ estimates using both methods and hope that future observational estimates (measuring directly the turbulent flux) can help guide the relative merits and accuracy of the two approaches. 

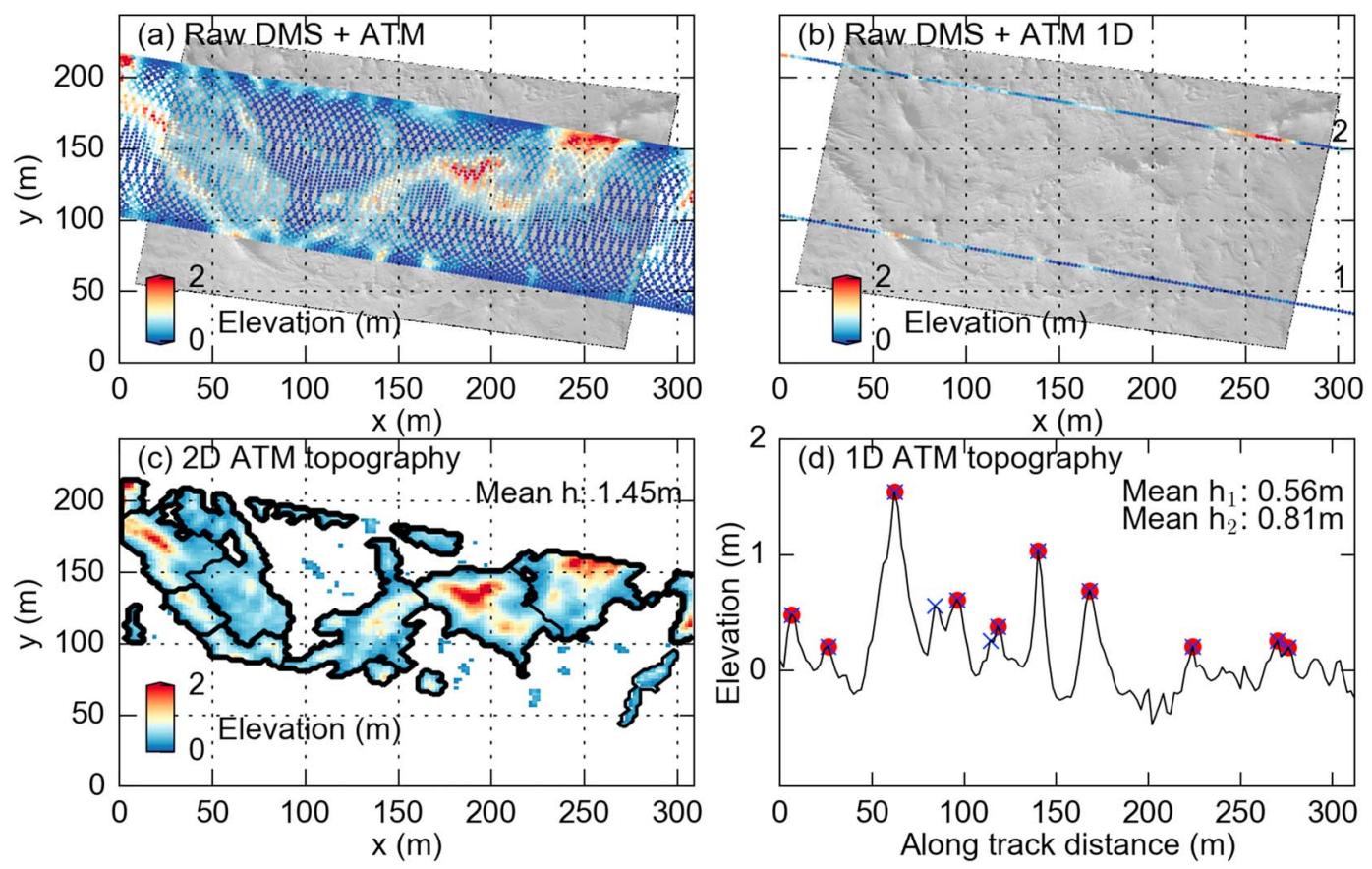

Figure 2. Comparison of the surface feature detection algorithms overlaid on a Digital Mapping System (DMS) image taken on the 23 March 2011 (location given by the yellow star in Figure 1) using the $(a, c)$ full scan method of Petty et al. [2016] and the (b, d) new linear profiling/Rayleigh Criterion method. The elevation in both cases is expressed relative to the estimated level ice surface found using the full scan data. The features in Figures $2 \mathrm{c}$ and $2 \mathrm{~d}$ are detected using a $20 \mathrm{~cm}$ elevation threshold. In Figure $2 \mathrm{~d}$ we only show the linear profiling results from line 1 for clarity, where all features detected are shown by the blue cross, and the unique features (separated by the Rayleigh Criterion) are shown by the red dots. The mean height of all features (within this section) using the full scan processing is given as "mean $\mathrm{h}$ " in Figure $2 \mathrm{c}$. The mean height of all features using the two linear profiles is given by "mean $\mathrm{h}_{1}$ " (line 1) and "mean $\mathrm{h}_{2}$ " (line 2) in Figure 2d.

\section{Results and Discussion}

\subsection{Full Scan and Linear Profiling Comparison}

4.1.1. Surface Feature Height

We first compare the surface feature height, $h_{f}$, estimates from the P2016 full scan method and the new linear profiling approach. The difference in methodology is demonstrated in the case study (23 March 2011) shown in Figure 2 (an additional example is provided in Figure S1). In this case study, the mean height of all features detected within the $\sim 1 \mathrm{~km}$ section is $1.45 \mathrm{~m}$ using the full scan (P2016) method, and $0.56 \mathrm{~m}$ using the new linear profiling method. Figure 2 highlights the idea discussed in the previous section that the full scan method is more likely finding the peaks of the surface features detected, with the linear profiling estimates profiling the feature heights more randomly. We briefly assess the impact from profiling the alternate edge of the swath (using data within an azimuthal range of $265-275^{\circ}$ ) and find a higher mean feature height of $0.81 \mathrm{~m}$. Beckers et al. [2015] explore in more detail the difference between scanning and linear profiling and the need to average over several kilometers to achieve convergence in estimates of surface roughness, although it is clear from the following results that the feature height and spacings across the two methods show large differences despite the use of a large averaging window $(10 \mathrm{~km})$.

Probability distributions of the raw individual feature heights from both methodologies are given in Figure 3. As in P2016, we exclude data within the Canadian Archipelago and Fram Strait (using the NSIDC Arctic Ocean mask) from all the probability distributions. The extra data are still included in the maps of $C_{\mathrm{da}, \mathrm{fr}}^{n}$ presented later. Note that the full scan distributions were also shown in P2016 but have been updated in this study to include the 2015 OIB data. The interannual variability of feature heights across the western Arctic were explored in P2016 so will be not be discussed in detail here.

Figure 3 demonstrates that the feature heights calculated using linear profiling have a lower modal height and a less pronounced tail (and thus a lower mean/median) than the full scan results. This is an important difference to consider when comparing the full scan P2016 results with previous, linear profiling studies 

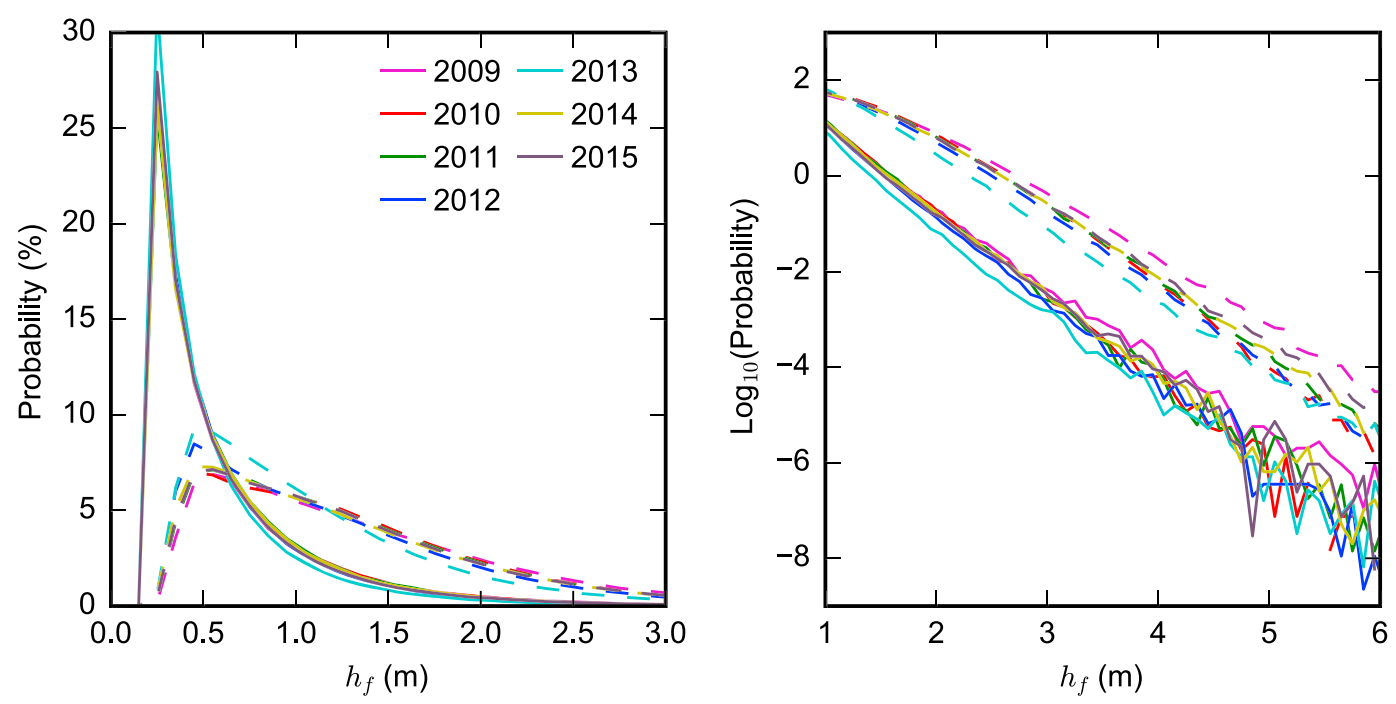

Figure 3. (left and right) Probability distributions of the surface feature height, $h_{f}$, using the full scan ice topography data (dashed lines) and the linear profiling topography estimates (solid lines) for all data within the Arctic Ocean. Both data sets use a $20 \mathrm{~cm}$ elevation threshold. Figure 3 (right) is the same as Figure 3 (left) but plotted on a logarithmic scale. Note that the $x$ axis is also expanded in the right to further highlight the tail of the distribution.

(e.g., C2014). A higher (lower) probability tail is still observable in 2009 (2013) in both linear and full scan distributions, demonstrating consistency in the interannual variability across the two methods. As discussed in P2016, an ordinary exponential distribution of sail heights was suggested based on previous observations [e.g., Wadhams and Horne, 1980], so Figure 3 also shows the distributions on a log linear scale. The log linear plots (using both full scan and linear profiling data) show that an exponential feature height distribution is present across both data sets (the data are linearly distributed when plotted on this logarithmic scale). The distributions from both methods are within the range (the gradient of the slope on the log linear scale) of those shown by Tucker et al. [1979] from sail height observations obtained using linear profiling across several Arctic sea ice campaigns in the 1970s. Our results show a stronger consistency in the distributions (but a clear difference between linear and full scan data), likely due to the fact we are profiling a similar, and broad, region of the western Arctic each year.

For the calculation of $C_{d a, f r}^{n}$, we use $10 \mathrm{~km}$ average quantities of feature height/spacing, as discussed earlier. The distributions using these averaged data for only the full scan data are shown in Figure 4. As in P2016, the distributions are presented for data within the Central Arctic (CA) and Beaufort/Chukchi (BC) regions (the regions are highlighted in Figure 1). The statistics of these distributions based on the linear profiling and full scan results in the CA and BC regions, and for all data within the NSIDC Arctic Ocean mask, are summarized in Table 1. The feature height statistics presented in Table 1 are thus slightly different to the statistics in P2016, as P2016 showed statistics using the raw individual feature height data. The differences in the mean values are small, as expected. The median/mode of the feature height distributions from the $10 \mathrm{~km}$ mean quantities are shown in the supporting information (Table S1). Note that we used a constant number of bins (50) within reasonable bounds of each variable when calculating the probability distributions, which resulted in bin widths of $10 \mathrm{~cm}\left(h_{f}\right), 10 \mathrm{~m}\left(D_{s}\right)$, and $0.1\left(C_{\mathrm{da}, \mathrm{fr}}^{n}\right)$. The modal values quoted in Table S1 are thus given at this resolution (the mean and median values use the unbinned $10 \mathrm{~km}$ data).

The mean feature heights from linear profiling are around half the height of the features detected using the full scan methodology ( $0.65 \mathrm{~m}$, linear profiling, compared to $1.33 \mathrm{~m}$, full scan), across all years of data within the Arctic Ocean region. The linear profiling results are similar to the results presented in C2014 that included a mean/mode feature height of $\sim 0.4-0.5 \mathrm{~m}$ for various profiles taken across the Arctic. The 2015 data (full scan) show a small decrease in feature heights in the CA region from 2014 to 2015 (1.39-1.37 m) but a strong increase in the $B C$ region (1.01 $\mathrm{m}$ to $1.16 \mathrm{~m})$. The linear profiling results agree well with the pattern of interannual and regional variability in the full scan data. 

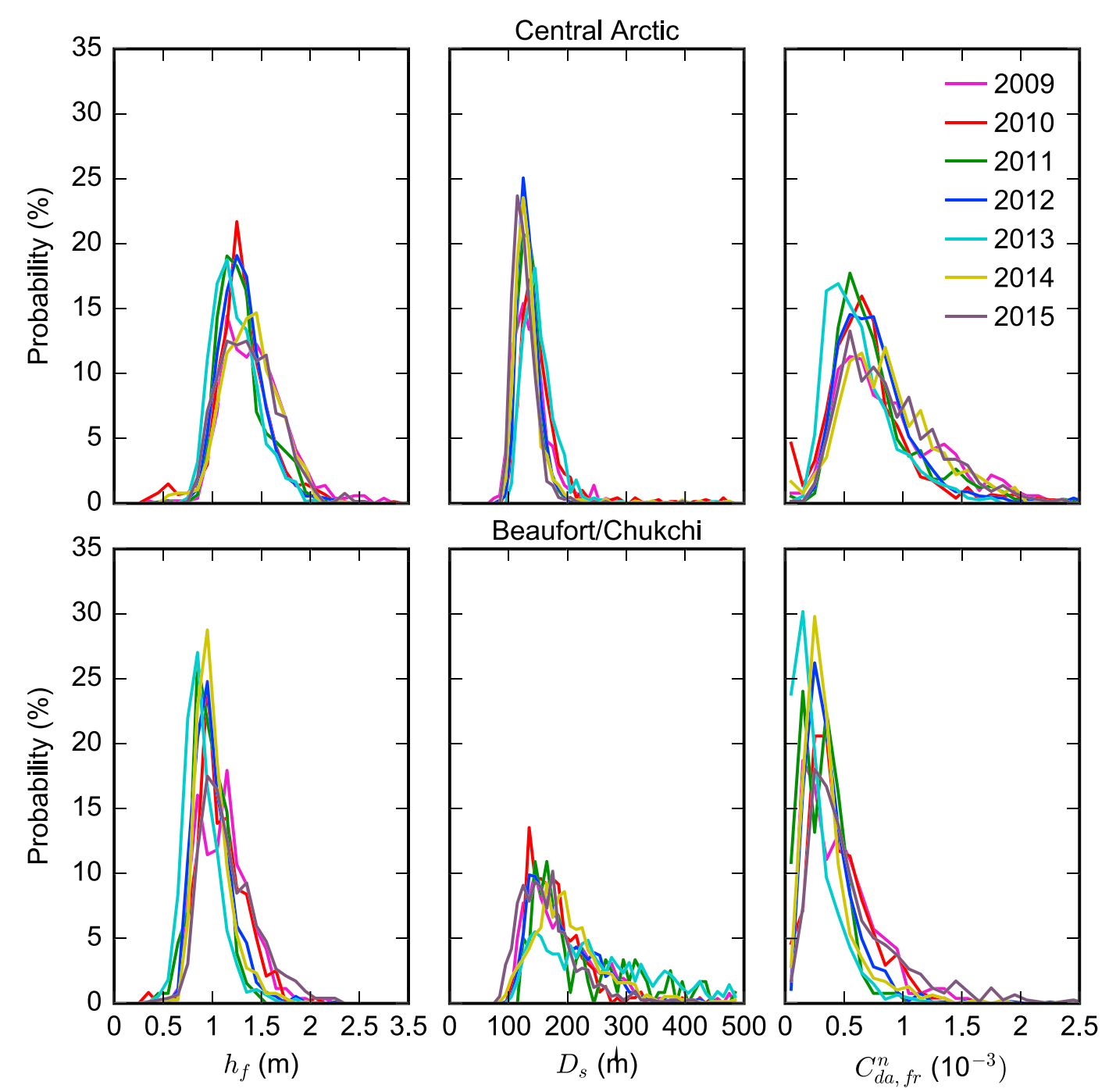

Figure 4. Probability distributions of the $10 \mathrm{~km}$ averages of surface feature height, $h_{f}$, spacing, $D_{s}$, and neutral atmospheric drag coefficient, $C_{\text {da,fr }}^{n}$ for the (top row) Central Arctic and (bottom row) Beaufort/Chukchi regions (shown in Figure 1) using the full scan topography data. A bin width of $10 \mathrm{~cm}, 10 \mathrm{~m}$, and 0.1 is used, respectively. The statistics mean/standard deviation (median/mode) of each distribution are summarized in Table 1 (S1).

\subsubsection{Surface Feature Spacing}

Two examples of the surface feature spacing, $D_{s}$, estimates using the full scan methodology are shown in Figure 5. In the first example, a long ridge feature is detected and separated into several ridge links, each characterized by thin ellipses of roughly equal length (the feature length is taken to be 2 times the length of the semimajor axis of the ellipse). In the second example (same as Figure 2) the features are characterized by ellipses of variable lengths and eccentricities (the ratio of eigenvalues of the covariance matrix $\mathbf{C}$, as discussed earlier). In general the ellipses appear to be flexible enough to broadly capture the broad variability in feature shapes and thus feature spacing, detected by the full scan approach.

The raw linear profiling data offer the potential to explore the distribution of ridges/features discussed in previous studies [e.g., Wadhams and Davy, 1986; Martin, 2007]. These studies both found that while sail/surface feature height distributions follow an exponential distribution (confirmed in this study and P2016), the sail spacings, or keel spacings in Wadhams and Davy [1986], are best characterized by a lognormal distribution. Note that while the Wadhams and Davy [1986] study was for ridge keel spacings, the results are expected to be broadly similar to sail spacing distributions if one assumes a reasonable level of isostasy (i.e., the peaks of individual sails and keels are broadly contiguous). The individual surface feature spacing distributions from 
Table 1. Mean Surface Feature Height, $h_{f}$, Feature Spacing, $D_{s}$, and Neutral Atmospheric Drag Coefficient, $C_{\text {da,fr }}^{n}$ Taken From the Probability Distributions Shown in Figure 4, Within the Central Arctic (CA), Beaufort/Chukchi (BC), and Arctic Ocean (AO) Regions ${ }^{\mathrm{a}}$

\begin{tabular}{|c|c|c|c|c|c|c|c|c|c|}
\hline \multirow[b]{2}{*}{ Year } & \multicolumn{3}{|c|}{$h_{f}(\mathrm{~m})$} & \multicolumn{3}{|c|}{$D_{s}(\mathrm{~m})$} & \multicolumn{3}{|c|}{$C_{\mathrm{da}, \mathrm{fr}}^{n}\left(10^{-3}\right)$} \\
\hline & CA & BC & $\mathrm{AO}$ & CA & BC & $\mathrm{AO}$ & CA & BC & $\mathrm{AO}$ \\
\hline & \multicolumn{9}{|c|}{ Linear } \\
\hline 2009 & $0.68(0.15)$ & $0.49(0.09)$ & $0.61(0.16)$ & $34.5(10.1)$ & $44.3(11.0)$ & $38.0(11.4)$ & $1.14(0.72)$ & $0.52(0.23)$ & $0.92(0.66)$ \\
\hline 2010 & $0.63(0.14)$ & $0.51(0.11)$ & $0.61(0.14)$ & $41.9(28.0)$ & $52.9(18.4)$ & $43.3(26.1)$ & $0.92(0.54)$ & $0.50(0.32)$ & $0.85(0.52)$ \\
\hline 2011 & $0.65(0.12)$ & $0.46(0.09)$ & $0.63(0.13)$ & $35.3(8.60)$ & $60.4(24.3)$ & $37.4(12.6)$ & $0.96(0.42)$ & $0.37(0.18)$ & $0.90(0.43)$ \\
\hline 2012 & $0.64(0.10)$ & $0.51(0.11)$ & $0.60(0.12)$ & $38.0(8.50)$ & $48.0(13.0)$ & $41.3(11.2)$ & $0.87(0.36)$ & $0.53(0.35)$ & $0.76(0.39)$ \\
\hline 2013 & $0.63(0.18)$ & $0.46(0.10)$ & $0.54(0.16)$ & 38.5 (12.9) & $56.1(26.1)$ & $47.6(21.9)$ & $0.84(0.37)$ & $0.42(0.27)$ & $0.61(0.37)$ \\
\hline 2014 & $0.68(0.21)$ & $0.53(0.10)$ & $0.62(0.19)$ & $40.2(14.5)$ & $49.4(16.8)$ & 43.9 (15.8) & $0.95(0.47)$ & $0.55(0.33)$ & $0.79(0.46)$ \\
\hline 2015 & $0.62(0.12)$ & $0.60(0.16)$ & $0.60(0.14)$ & $34.6(6.90)$ & $41.6(12.0)$ & $37.9(10.1)$ & $0.89(0.32)$ & $0.78(0.51)$ & $0.83(0.43)$ \\
\hline \multirow[t]{2}{*}{ All } & $0.65(0.15)$ & $0.51(0.12)$ & $0.60(0.15)$ & $37.9(14.1)$ & 49.5 (19.1) & 41.9 (16.6) & $0.93(0.45)$ & $0.54(0.37)$ & $0.79(0.46)$ \\
\hline & \multicolumn{9}{|c|}{ Full Scan } \\
\hline 2009 & $1.44(0.34)$ & $1.11(0.26)$ & $1.33(0.35)$ & $147.0(83.1)$ & $196.8(88.0)$ & $161.5(83.4)$ & $0.96(0.65)$ & $0.47(0.29)$ & $0.79(0.58)$ \\
\hline 2010 & $1.30(0.29)$ & $1.08(0.24)$ & $1.26(0.29)$ & $191.1(176.2)$ & 199.5 (125.8) & $187.6(155.8)$ & $0.70(0.40)$ & $0.45(0.25)$ & $0.65(0.37)$ \\
\hline 2011 & $1.30(0.25)$ & $0.96(0.17)$ & $1.26(0.26)$ & $137.6(65.2)$ & $254.2(146.6)$ & $151.6(86.4)$ & $0.78(0.37)$ & $0.31(0.18)$ & $0.72(0.38)$ \\
\hline 2012 & $1.31(0.25)$ & $1.01(0.21)$ & $1.19(0.27)$ & $133.9(21.0)$ & $194(68.0)$ & $157.7(55.9)$ & $0.77(0.38)$ & $0.38(0.24)$ & $0.62(0.37)$ \\
\hline 2013 & $1.24(0.31)$ & $0.89(0.19)$ & $1.06(0.30)$ & $154.4(53.4)$ & 349 (244.3) & 253.7 (201.9) & $0.63(0.29)$ & $0.24(0.20)$ & $0.42(0.31)$ \\
\hline 2014 & $1.39(0.31)$ & $1.01(0.18)$ & $1.23(0.33)$ & $141.9(73.4)$ & $214.3(105.7)$ & $173.0(96.3)$ & $0.88(0.42)$ & $0.36(0.24)$ & $0.66(0.44)$ \\
\hline 2015 & $1.37(0.30)$ & $1.16(0.29)$ & $1.26(0.31)$ & $129.4(51.3)$ & $183.9(115.2)$ & $156.2(90.7)$ & $0.90(0.44)$ & $0.57(0.42)$ & $0.73(0.46)$ \\
\hline All & $1.33(0.29)$ & $1.02(0.24)$ & $1.21(0.31)$ & $146.3(85.1)$ & $234.3(160.7)$ & $179.2(124.3)$ & $0.80(0.43)$ & $0.39(0.30)$ & $0.64(0.43)$ \\
\hline
\end{tabular}

${ }^{\text {a }}$ The values in brackets represent one standard deviation of the relevant distribution.

linear profiling are shown in Figure 6, including the distributions plotted on a log linear scale. We can see qualitatively that the data do not follow an exponential distribution (the distribution is not linear on this log scale), but to test this further, we fit both an exponential and lognormal distribution to the raw spacing data (for all years of data). The strong match between the lognormal fit and the raw data provide further evidence of the presence of a lognormal distribution in pressure ridge/surface feature spacings using linear profiling.

The $10 \mathrm{~km}$ averaged surface feature spacing distributions calculated using both the full scan and linear profiling methods are shown in Figure 4. The mean (median/mode) values of the distributions are summarized in Table 1 (S1). We can see from Figure 4 and Table 1 that the feature spacings using linear profiling are lower than the full scan feature spacings by roughly a factor of 4 (e.g., a mean of $42 \mathrm{~m}$, linear, compared to $179 \mathrm{~m}$, full scan, for all years of data within the Arctic Ocean).
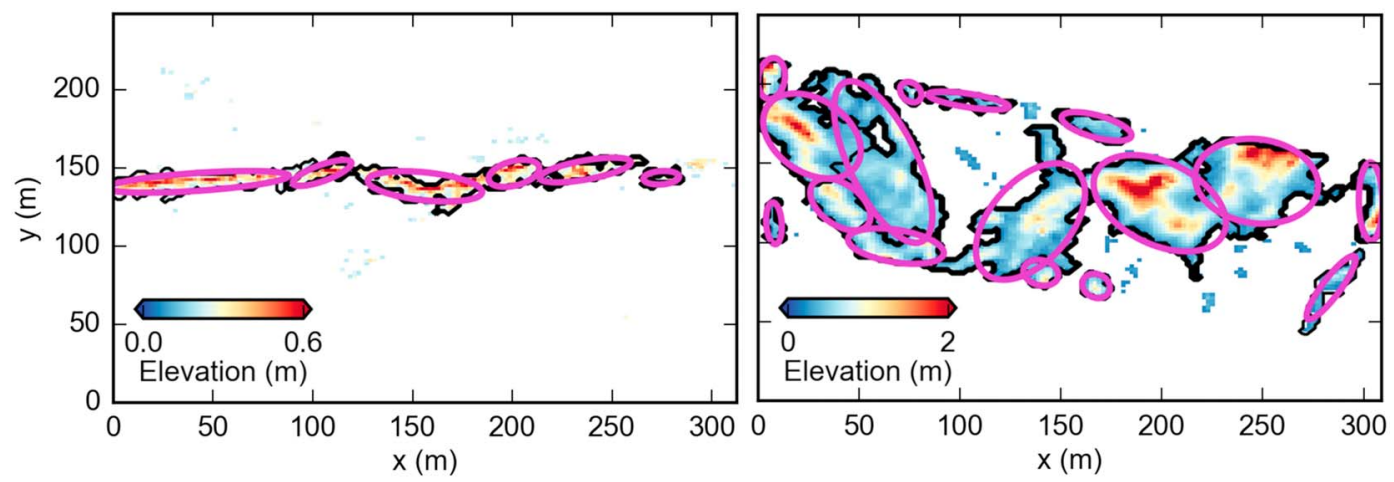

Figure 5. Examples of the elliptical surface feature characterization. The elevations are expressed relative to the estimated level ice surface in each example; the black lines denote the individual features detected; the magenta ellipses represent the features characterized by their individual feature covariance matrix. Both examples are from the 23 March 2011 (location given by the yellow star in Figure 1). 

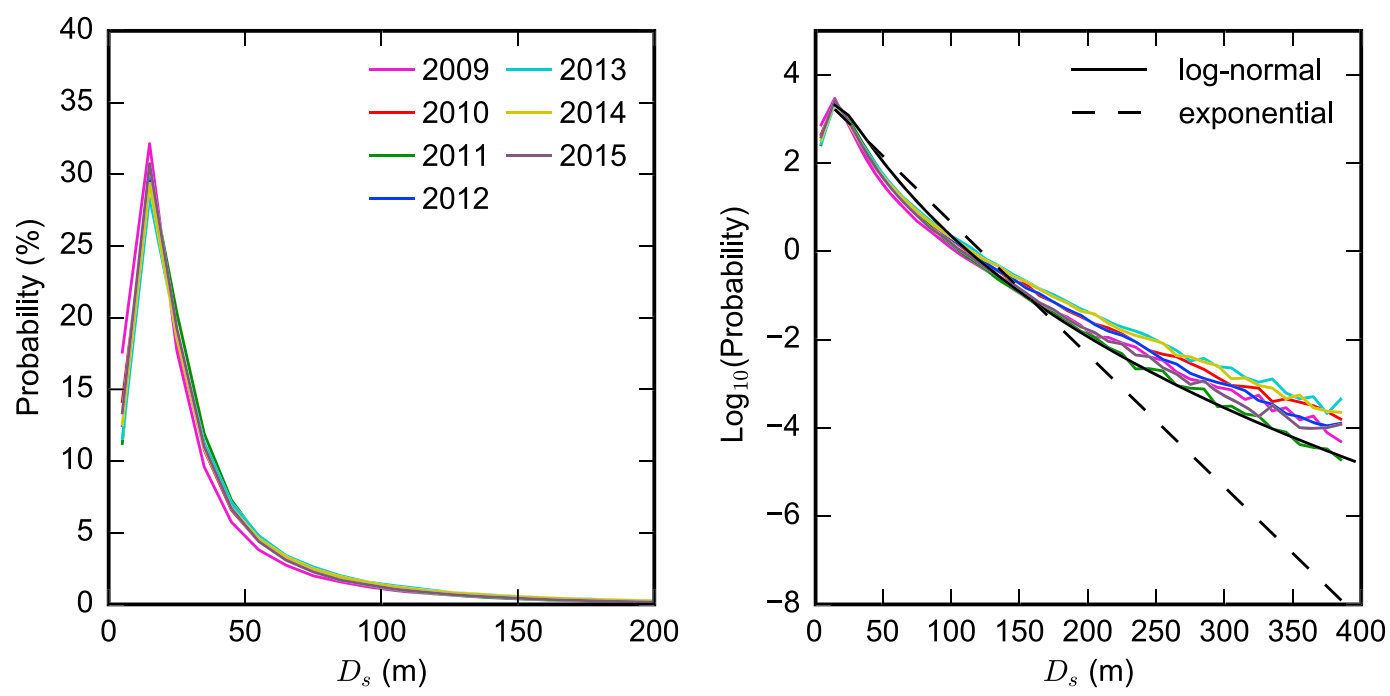

Figure 6. (left and right) Probability distributions of the surface feature spacing, $D_{s}$, using linear profiling, for all data within the Arctic Ocean using a $20 \mathrm{~cm}$ elevation threshold. As in Figure 3, Figure 6 (right) is the same as Figure 6 (left) but plotted on a logarithmic scale. Note that the $x$ axis is also expanded in the right to further highlight the tail of the distribution. The solid black and dashed lines show exponential and lognormal distributions fit to the data across all years.

As shown in Figure 4 (and Table 1), the feature spacing is higher in the $B C$ region compared to the CA region, and the strength of the regional difference appears to be broadly consistent across both methods (e.g., feature spacings roughly twice as large in the $B C$ compared to the $C A$ region in 2013). The pattern of interannual variability is also consistent across methods and shows an inverse pattern to the feature heights (i.e., high feature spacings coincide with low feature heights as expected). Note that maps of the feature spacings using the full scan data are shown in the supporting information (Figure S2), further highlighting the regional difference in feature spacing. Note that the C2014 distributions show a modal feature spacing (using linear profiling) of $\sim 20 \mathrm{~m}$ across most of their study regions. The modal spacings from linear profiling in this study (Table S1) are around $35 \mathrm{~m}$ (all Arctic data) so higher than the C2014 distributions. It is remarkable to note the interannual consistency in the modal feature spacing $(35 \mathrm{~m})$ in the Arctic and CA distributions, with moderate interannual variability observed in the modal $B C$ feature spacing. The variability in the mean feature spacing is thus thought to be driven primarily by variability in the tail of the distribution across both methods. It is also worth noting that while the feature height change from 2014 to 2015 in the CA region was small, the feature spacings show a more significant decrease (142-129 $\mathrm{m}$ in the full scan data).

It is unclear why the feature spacing data are so different across the two methods, as the linear profiling estimates are based on a linear approximation of the two-dimensional ridging density estimates [Mock et al., 1972; Arya, 1973]. As discussed in section 3.1.1, most studies to date have provided feature spacing estimates using linear profiling. However, the original theory of Arya [1975] assumed measurements of the two-dimensional ridging density. The Arya [1973] results for ridging density, converted into feature spacing using equation (5), give spacings of $\sim 120 \mathrm{~m}$ in the Beaufort/Chukchi Seas in the 1960s, within the range of the full scan spacing results shown in our study.

Before we calculate the form drag coefficient, the feature height and spacing data also allow us to estimate a ridging intensity, $R_{i}$, parameter. The ridging intensity is used in several studies as a proxy for form drag and is also used to classify different ice deformation regimes [e.g., Arya, 1973; Lewis, 1993; Dierking, 1995; Martin, 2007; Tan et al., 2012]. Based on the differences in feature height and spacing in our two methods we see a near doubling of $R_{i}$ across the two methods $(0.016$, linear profiling and 0.008 , full scan) using all years of data within the Arctic Ocean region. Note that a ridging intensity threshold of 0.015 is used in Martin [2007] (based on linear profiling data) to separate less deformed and heavily ridged ice, a value between the mean $B C(0.012)$ and CA (0.019) estimates found in this study. We show the results for all years and regions in the supporting information (Table S2) for those interested in comparing with previous studies but choose to focus on the calculation and comparison of form drag below for simplicity. 


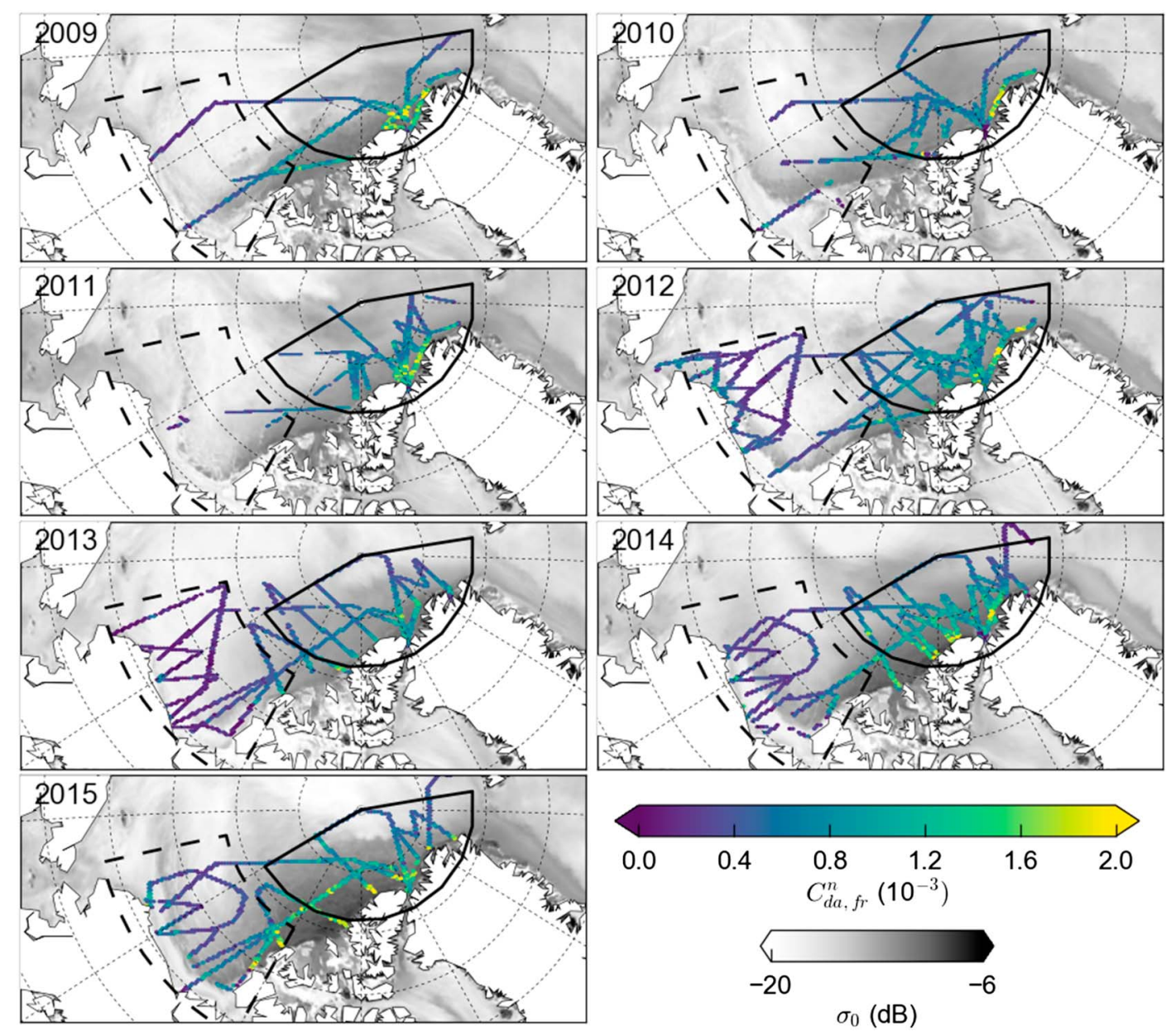

Figure 7. Neutral atmospheric form drag coefficient from surface features, $C_{d a, f r}^{n}$, from 2009 to 2015 , estimated using the full scan ice topography data. The results are overlaid on the mean ASCAT radar backscatter $(\sigma 0)$ over the relevant spring IceBridge sea ice campaign time period. The solid (dashed) black lines represent the Central Arctic (Beaufort/Chukchi) regions used in this study. The data are plotted using hexagonal bins.

\subsubsection{The Neutral Atmospheric Form Drag Coefficient}

The neutral atmospheric form drag coefficient from surface features, $C_{\mathrm{da}, \mathrm{fr}}^{n}$, was calculated using equation (4) for both full scan and linear profiling estimates of feature height and spacing. The regional distributions using the full scan data are shown in Figure 4, with the distributions using the linear profiling data shown in the supporting information (Figure S3). The statistics using both methods are summarized in Table 1 and S1. Maps of $C_{\text {daff }}^{n}$ from 2009 to 2015 using the full scan data are given in Figure 7. In this study, we estimate a mean (2009-2015) $C_{\text {da,fr }}^{n}$ of $0.79 \times 10^{-3}$ (linear) and $0.64 \times 10^{-3}$ (full scan) across the western Arctic in spring.

The maps highlight the strong regional variability and moderate interannual variability of $C_{\text {dafr }}^{n}$ within the $B C$ and CA regions. $C_{\text {da,fr }}^{n}$ is higher in the CA region, as expected, including a mean of $0.93 \times 10^{-3}$ (linear) and $0.80 \times 10^{-3}$ (full scan). The BC $C_{\mathrm{da}, \mathrm{fr}}^{n}$ estimates are around half the $C A$ values $\left(0.54 \times 10^{-3}\right.$, linear, and $0.39 \times 10^{-3}$, full scan). Both regions show moderate interannual variability, with the highest $B C$ (CA) estimates found in 2015 (2009). As discussed in P2016, however, the 2009 flights in the CA region were biased more toward the coastline, where it is expected that the ice age/thickness and thus deformation is highest (discussed more in the following section).

Note in general how the higher (lower) estimates of feature heights (spacing) in the full scan data broadly compensate each other to produce similar estimates of $C_{\text {dafr }}^{n}$ compared to the linear profiling results. This can be explained by the ratio $h_{f} / D_{s}$ in equation (4) and the extra $h_{f}$ term, meaning more weight is given to the smaller differences in feature height over the larger differences in feature spacing across the two methods. This result is demonstrated qualitatively by Figure 8 , which shows maps of the feature height, spacing, and drag 

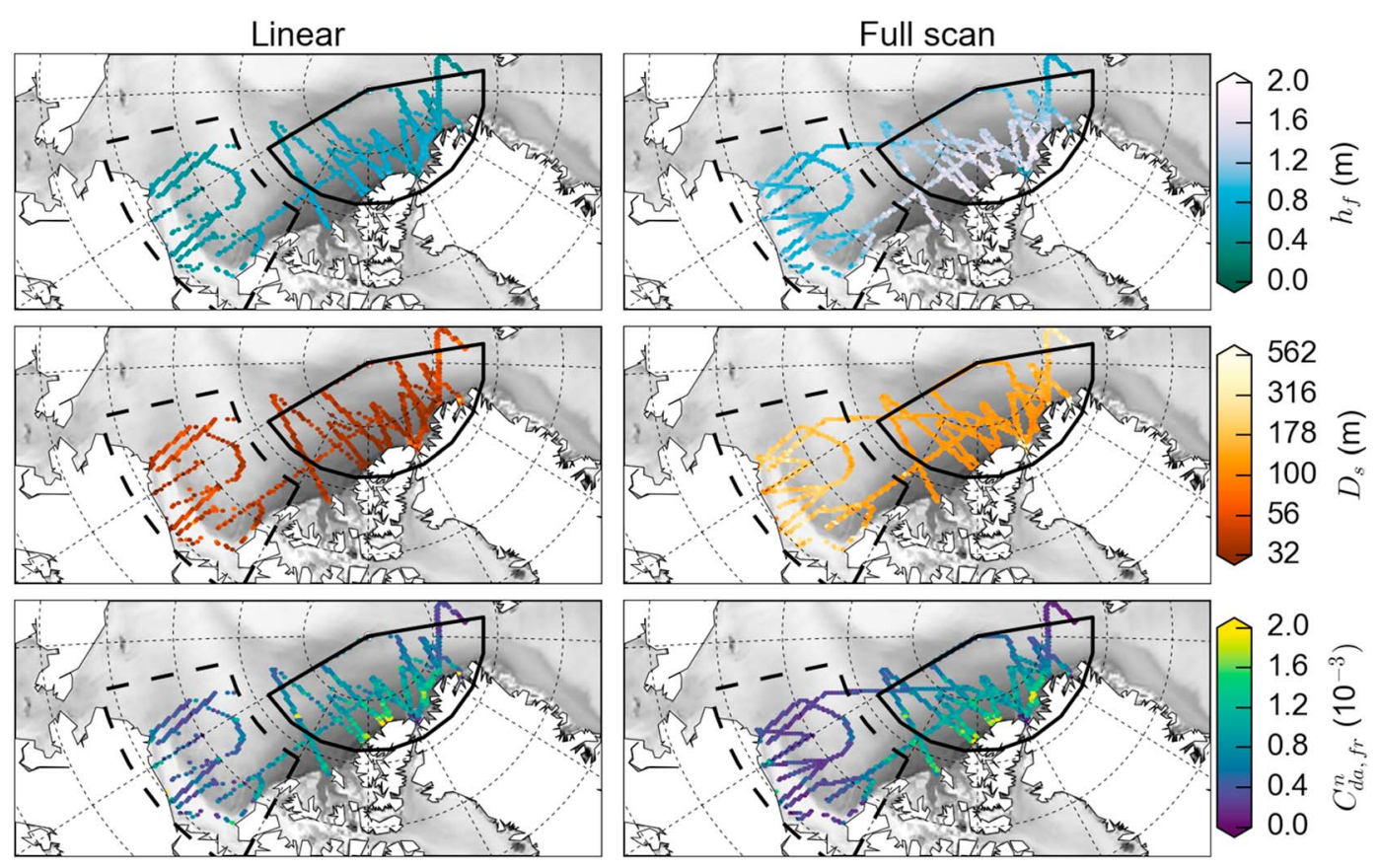

Figure 8. Comparison of the 2014 surface feature height, $h_{f}$, spacing, $D_{s}$, and neutral atmospheric form drag coefficient from surface features, $C_{\text {da fr }}^{n}$, estimates using the (left) linear profiling and (right) full scan methodology. The results are overlaid on the mean ASCAT radar backscatter over the same 2014 spring IceBridge sea ice campaign time period. The solid (dashed) black lines indicate the Central Arctic (Beaufort/Chukchi) regions used in this study. The data are plotted using hexagonal bins. Note that the feature spacing results are plotted on a logarithmic scale.

coefficient in 2014 using the linear and full scan data. The difference in feature height and spacing is clearly visible across the two methods (bigger differences than the regional variability), but the regional variability of $C_{\text {dafr }}^{n}$ across the two methods is broadly similar. In general our full scan results are lower than the estimates produced using linear profiling by $\sim 10-20 \%$.

P2016 discussed the increase in feature height within the CA region from 2013 to 2014, which they linked to increases in the convergent driven ice growth estimated in Kwok [2015]. Our results suggest that this also coincided with a decrease in feature spacing (i.e., an increase in the feature density) and thus an increase in $C_{\text {da,fr }}^{n}$. From 2014 to 2015 , the full scan results suggest a leveling off in feature heights but a further decrease in feature spacing, resulting in a small additional increase in $C_{\text {da,fr }}^{n}\left(0.88\right.$ to $\left.0.90 \times 10^{-3}\right)$. The maps (Figure 7 ) suggest that this increase in $C_{d a, f r}^{n}$ is stronger/more prevalent in the western Central Arctic (toward the Beaufort Sea).

It is challenging to compare our linear profiling results directly with C2014, as their spatial coverage is limited and many of their data sets were obtained from campaigns prior to 2009, when the ice age was higher across the Arctic [e.g., Maslanik et al., 2011]. However, their 2011 Central Arctic estimate of $\sim 1.0 \times 10^{-3}$ appears to be broadly in line with our results. It is also worth noting that C2014 state that their mean drag estimates in the Beaufort Sea based on linear profiling data obtained in 1998, during the Surface Heat and Energy Budget of the Arctic project, compared well with direct turbulent flux measurements over the same site. Note that C2014 quote the total neutral drag coefficient from the addition of the variable form drag and a constant skin drag (which they take to be $0.8 \times 10^{-3}$ ) which we subtracted here to enable a more direct comparison. As discussed in C2014, the variable snow cover can also provide a significant impact on drag by sheltering smaller surface roughness features. As the OIB data are collected in early spring, a substantial snow cover will likely be prevalent across most of the regions profiled, and this should be considered when comparing to studies at different times of the year. This is also an issue when comparing estimates taken decades apart, when the Arctic snow cover is thought to have undergone significant change [e.g., Webster et al., 2014].

For the rest of this study we choose to focus solely on the full scan results for simplicity. As stated in section 3.1.1, the most appropriate method/data to drive the parameterization in equation (4) is still unclear. While we have not attempted to demonstrate that one method is better/more appropriate, due to a lack of comparative data sets and direct measurements of the wind drag over large regions of the Arctic, the full 


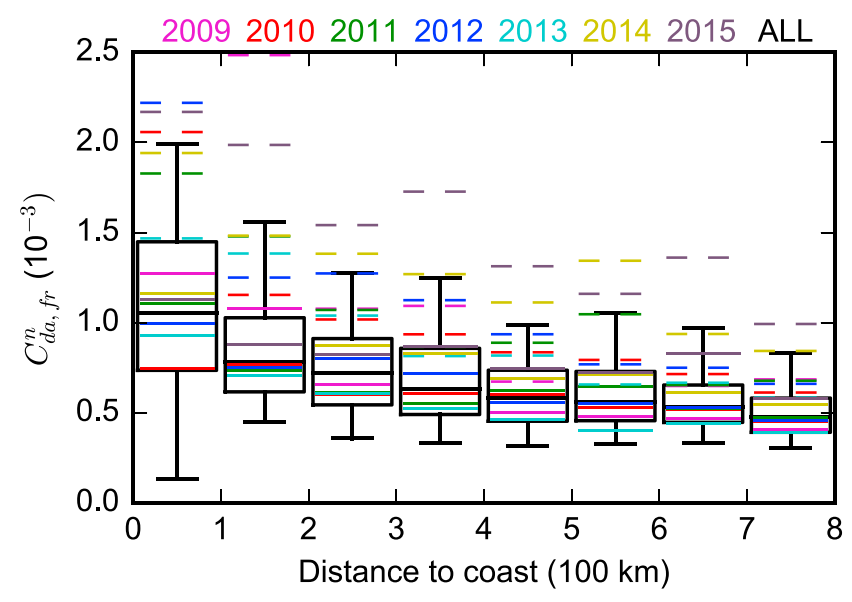

Figure 9. Box and whisker plots of the neutral atmospheric form drag coefficient from surface features, $C_{\text {da.fr' }}^{n}$ as a function of the distance to the nearest coastline within the Central Arctic region. The coastline distance bin width is $100 \mathrm{~km}$. The black boxes (25th, 50th, and 75th percentiles) and whiskers (5th and 95th percentiles) show the 2009-2015 (ALL) data. The solid (dashed) colored lines show the median (95th percentile) for each year. scan data make use of more of the ATM data, better capture the full structure of the surface features, and are expected to be less prone to random sampling errors than the linear profiling results. What we require in future is a validation of these estimates using, for example, direct measurements of the turbulent flux over different sea ice regimes. As turbulent flux measurements integrate both skin and form drag, we require data over a variety of surface types (including flat level ice to assess the contribution from skin drag), with stability effects considered, to help validate the results presented here.

\subsection{The Neutral Atmospheric Form Drag Coefficient as a Function of Coastline Proximity}

Figure 7 highlights the increase in $C_{d a, f r}^{n}$ toward the coasts of northern Greenland and the Canadian Archipelago. The topography relationship was explored in P2016 as the convergent, onshore, ice drift in the CA region is thought to contribute significantly to increases in ice deformation/thickness [e.g., Kwok, 2015] and age [e.g., Maslanik et al., 2011]. Figure 9 shows $C_{\text {da,fr }}^{n}$ represented by box and whisker plots, separated into coastline proximity bins (100 km wide) for the CA region. We choose to focus on the $C A$ region as only a weak coastal ice topography dependance was found in the $B C$ region in P2016. A map of the coastline proximity is given in the supporting information of P2016. We see that the median $C_{\mathrm{da}, \mathrm{fr}}^{n}$ within each $100 \mathrm{~km}$ bin increases monotonically with coastline proximity, from $\sim 0.45 \times 10^{-3}$ in the $800-900 \mathrm{~km}$ proximity bin (toward the North Pole) to $\sim 1.10 \times 10^{-3}$ in the $0-100 \mathrm{~km}$ proximity bin (along the CA coastline). The maximum (95th percentile) values in the $0-100 \mathrm{~km}$ bin are $\sim 2.0 \times 10^{-3}$. Note that C2014 found a mean value of $1.8 \times 10^{-3}$ within the Lincoln Sea, although these were from data collected in 2004/2005 and the median value is expected to be lower than the mean considering the shape of the distribution.

\subsection{Extrapolating the Neutral Drag Coefficient Estimates With Satellite Radar Backscatter Data} Here we investigate the extrapolation of the OIB $C_{d a, f r}^{n}$ estimates using ASCAT satellite radar backscatter data. The ASCAT backscatter data are shown in Figure $\mathrm{S4}$, and it is again worth noting that these are averages over the relevant spring OIB sea ice campaign time periods. We fit a function of the form $C_{\mathrm{da} \text {,fr }}^{n}=A e^{\sigma_{0} B}$ where $\sigma_{B}$ is the ASCAT radar backscatter and $A$ and $B$ are constants found using a least squares regression. Note that we experimented with polynomial fits, but the exponential relationship provided higher correlations in general and minimized the number of coefficients needed to be found. We find the Pearson product moment correlation coefficient $(r)$ between the ASCAT backscatter and the OIB $C_{d a, f r}^{n}$ estimates each year using the exponential relationship and constants $(A$ and $B$ ). We also calculate the correlation ( $r$ value) between the OIB $C_{\mathrm{da}, \mathrm{fr}}^{n}$ and ASCAT data using the constants found using all years of data (2009-2015) to explore whether a consistent relationship can be used and applied across different time periods. Note that in the regression analysis, the OIB $C_{\mathrm{da}, \mathrm{fr}}^{n}$ estimates are averaged over $25 \mathrm{~km}$ sections, and the ASCAT data are interpolated onto these data using a nearest neighbor interpolation scheme. When producing the ASCAT $C_{\mathrm{da}, \mathrm{fr}}^{n}$ estimates (using the regression equation shown above), the raw $(4.5 \mathrm{~km})$ data are used.

The annual regressions (and the regression using the 2009-2015 data) are shown in Figure 10. The correlation using all years of data (2009-2015) is strong $(r=0.79)$, with the highest annual correlation (2011) only slightly higher $(r=0.84)$. The correlation was weakest for the 2010 regression $(r=0.58)$. Perhaps surprisingly, the regressions using the constants $(A$ and $B)$ found using all years of data produced correlations of the same strength (given in brackets in Figure 10). The high strength of the correlation between the ASCAT backscatter and the OIB $C_{d a, f r}^{n}$ estimates gives us confidence in our ability to extrapolate the $C_{d a, f r}^{n}$ across the Arctic Ocean. 

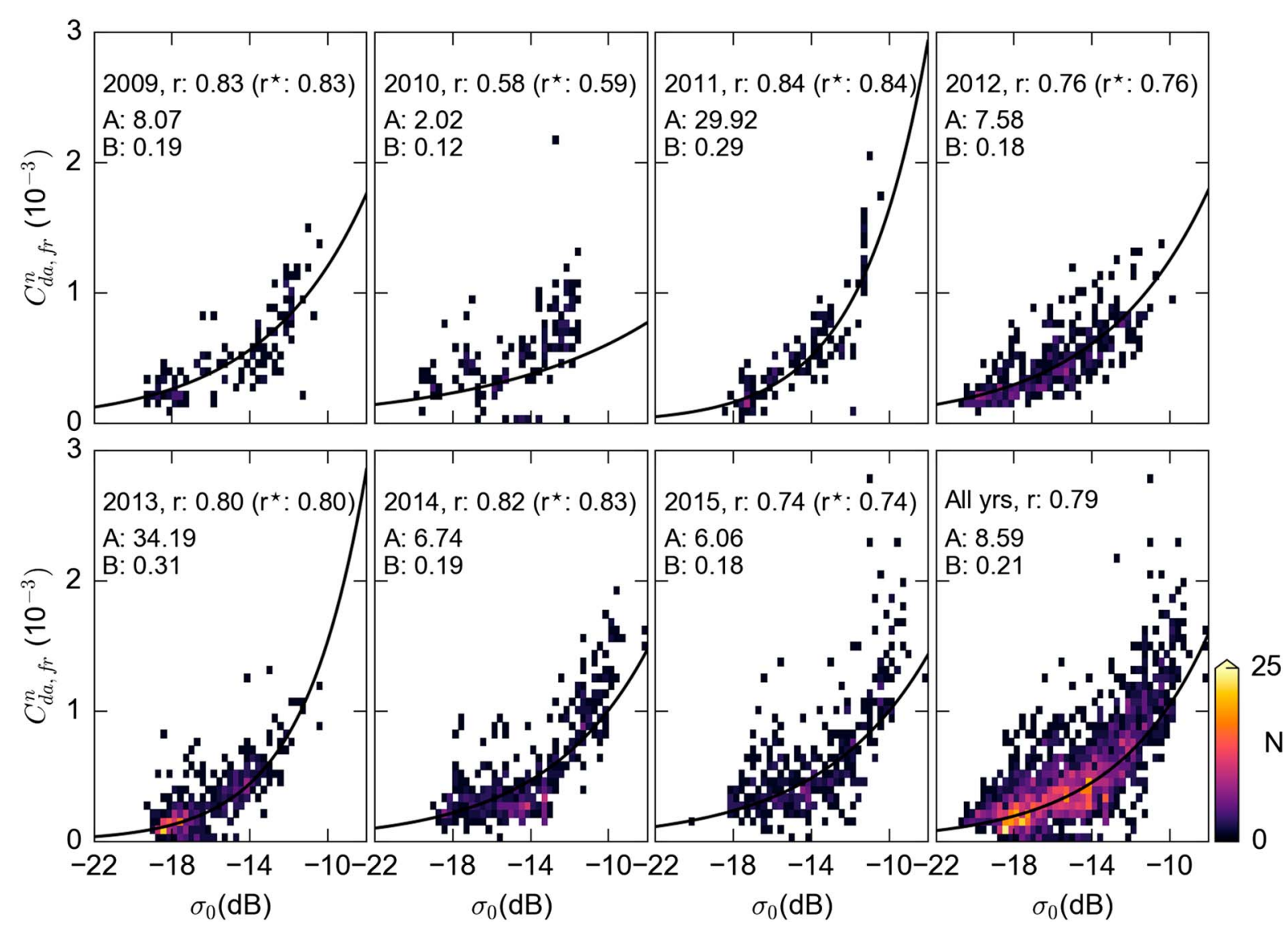

Figure 10. Regressions between the ASCAT radar backscatter data and the neutral atmospheric form drag coefficient from surface features, $C_{\text {da,fr' }}^{n}$ for each year and all years combined (All years). The solid lines represent the least squares fit assuming an exponential relationship $C=A e^{B \sigma_{0}}$. The coefficients $A$ and $B$ and the correlation coefficient $(r)$ are given in each panel. The $r$ value in brackets is the correlation coefficient calculated using the coefficients found using all years of data $(A=8.59$ and $B=0.21)$. The data in each panel are plotted as a heat map, where $N$ refers to the number of points in each bin.

We believe that the high correlations are due primarily to the high spatial coverage of the OIB data, which have profiled a large range of surface scattering regimes each spring. We expect more localized analyses to be more sensitive to annual changes in volume scattering in the radar backscatter signal (due to changes in the ice age), which is something worth considering in future work.

The extrapolated ASCAT $C_{d a, f r}^{n}$ estimates are given in Figure 11 providing, to our knowledge, the first pan-Arctic estimates of the neutral atmospheric form drag coefficient from ice topography variability. We mask the data below on ice concentration threshold of 0.95 using the NASA Team concentration data, as the contribution to form drag from floe edges is thought to become significant below this threshold [e.g., Lüpkes et al., 2012]. This is especially important in the following section when we combine the extrapolated ASCAT estimates with a concentration-based drag parameterization, as we want to avoid double counting of the contribution from floe edges, which could also influence the radar backscatter signal. The results across the eastern Arctic should be considered with caution as no OIB data were obtained within this part of the Arctic. However, the smooth, first-year, ice pack which dominates the eastern Arctic is expected to be broadly similar to the younger ice cover of the $\mathrm{BC}$ region. The maps make physical sense in general, with higher $C_{d a, f r}^{n}$ in the Central Arctic (as in Figure 7), mainly along the Canadian Archipelago coastline, as opposed to the northern Greenland (Lincoln Sea) coast. Figure 11 suggests moderate interannual variability in the extension of higher $C_{\mathrm{da}, \mathrm{fr}}^{n}$ values into the eastern Arctic (more prominent in 2010, 2011, and 2014). The maps also provide additional qualitative evidence of the strong increase in $C_{d a, f r}^{n}$ north of Greenland and the Canadian Archipelago from 2013 to $2014 / 2015$, as discussed previously in the full scan CA analysis. The results also suggest that a significant 

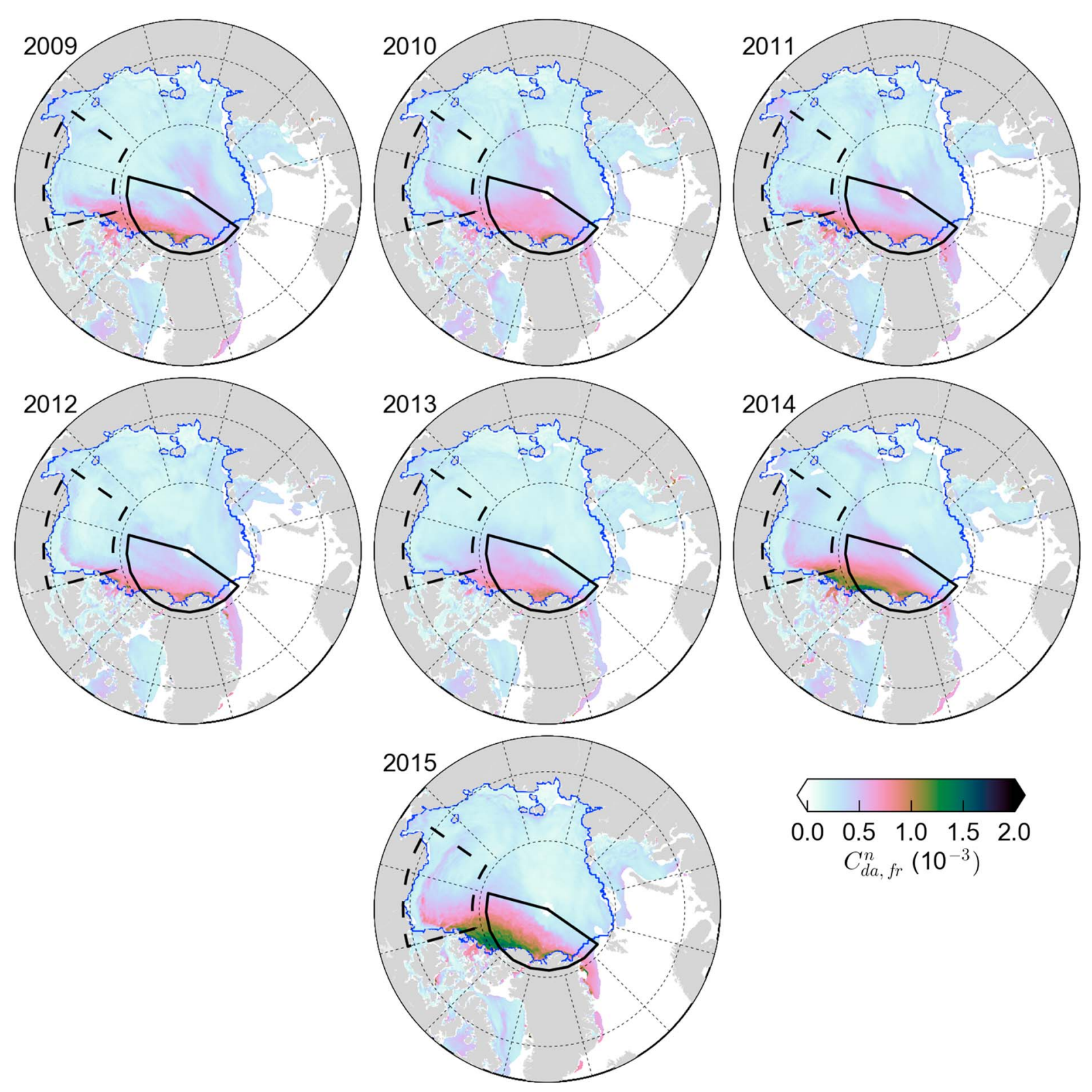

Figure 11. Estimates of the neutral atmospheric form drag coefficient from surface features, $C_{\mathrm{da} \text {, fr }}^{n}$, estimated using the ASCAT radar backscatter data from the relevant spring IceBridge sea ice campaign time period, and the ASCAT/OIB regression equation shown in Figure 10. The solid (dashed) black lines indicate the Central Arctic (Beaufort/Chukchi) regions, while the blue line shows the NSIDC Arctic Ocean region mask.

part of the 2013 to $2014 / 2015$ increase takes place in a small region between the BC and CA study regions. The extrapolated $C_{d a, f r}^{n}$ estimates in this region in 2015 show the highest values across our entire 2009-2015 analysis.

\subsection{The Total Atmospheric Neutral Drag Coefficient}

Finally, we combine our $C_{d a, f r}^{n}$ results with existing parameterizations of the form drag from floe edges within the unconsolidated $\mathrm{MIZ}, C_{\mathrm{da}, \mathrm{ff}^{\prime}}^{n}$ skin drag over level ice, $C_{\mathrm{da}, \mathrm{s}^{\prime}}^{n}$ and the total drag over open water, $C_{d a, w^{\prime}}^{n}$ to produce estimates of the pan-Arctic total neutral atmospheric drag coefficient in early spring (the relevant spring OIB sea ice campaign time period), as

$$
C_{\mathrm{da}}^{n}=(1-A) C_{\mathrm{da}, \mathrm{w}}^{n}+A C_{\mathrm{da}, \mathrm{s}}^{n}+3.67 A(1-A)+A C_{\mathrm{da}, \mathrm{fr}}^{n},
$$



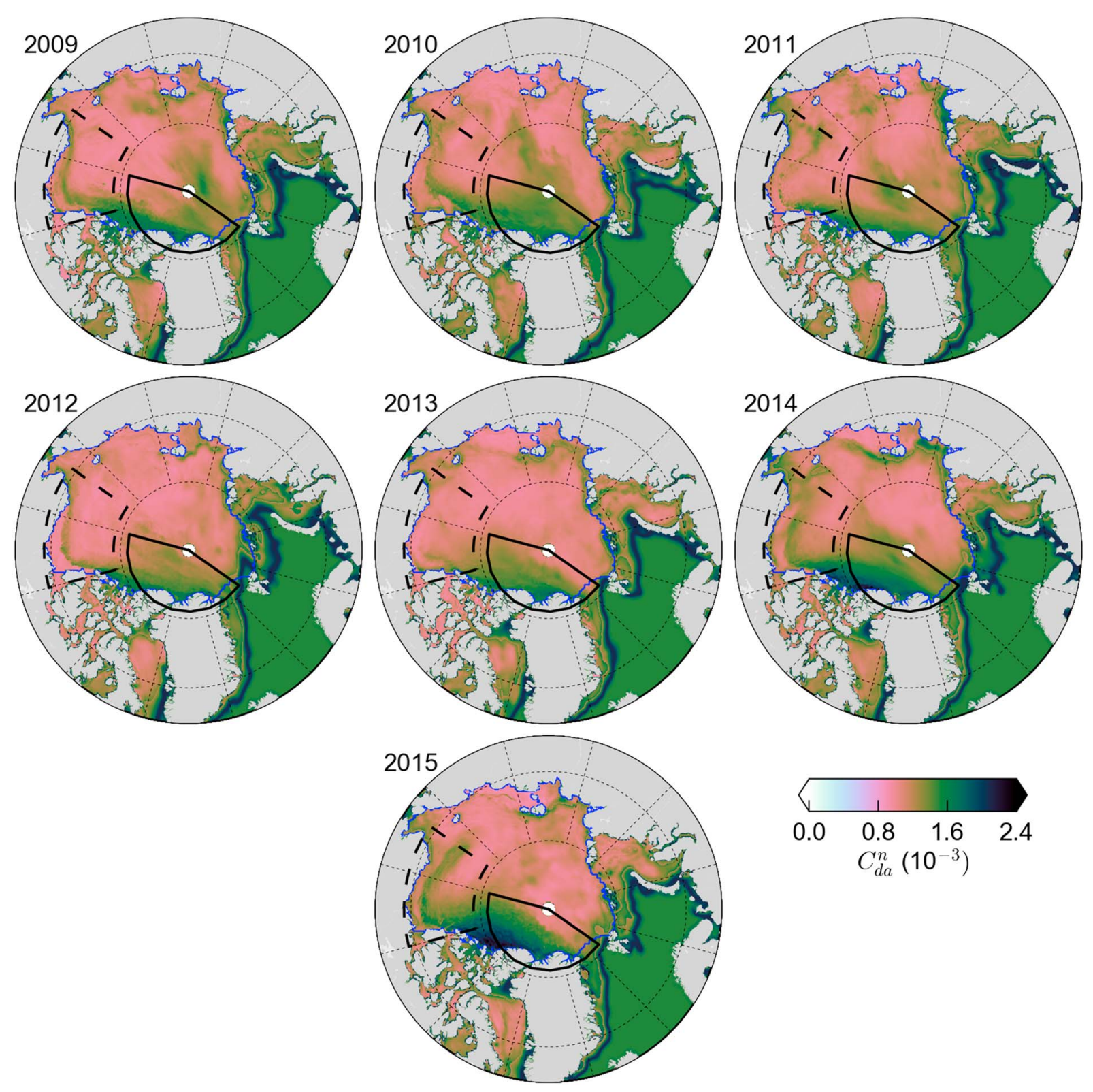

Figure 12. Estimates of the total neutral atmospheric drag coefficient, $C_{\mathrm{da}}^{n}$ from the relevant IceBridge sea ice campaign time period, estimated using a combination of the form drag coefficient from surface features, $C_{\mathrm{da}}^{n}$,fr (as shown in Figure 11), form drag from floe edges in the marginal ice zone, skin drag, and the drag over open water (given in equation (7)).The solid (dashed) black lines indicate the Central Arctic (Beaufort/Chukchi) regions, while the blue line shows the NSIDC Arctic Ocean region mask.

where $C_{d a, w}^{n}$ is the neutral atmospheric drag coefficient over open water (given as $1.5 \times 10^{-3}$ as in Lüpkes et al. [2012]). $C_{\mathrm{da}, \mathrm{s}}^{n}$ is the skin drag coefficient over level ice, which is given in Lüpkes et al. [2012] as $1.4 \times 10^{-3}$. However, as the value in Lüpkes et al. [2012] is thought to include the impact from ice topography (more representative of a total neutral drag over consolidated ice), we instead follow C2014 (based on Garbrecht et al. [2002]) and use a lower value for the skin drag over level ice, $C_{d a, s^{\prime}}^{n}$ of $0.8 \times 10^{-3}$. The third term in equation (7) represents a parameterization of the form drag from floe edges, $C_{\mathrm{da}, f^{\prime}}^{n}$ following the simple ice concentration-based parameterization given in Lüpkes et al. [2012, equation (37)]. Note that more complex formulations are given in Lüpkes et al. [2012], but this was seen to be the most appropriate for our first-order analysis. The last term in equation (7) is the $C_{d a, f r}^{n}$ value as calculated in this study (the ASCAT extrapolated OIB data). Note that this final term is only given for concentrations above 0.95 (as in the maps in Figure 10). 
Table 2. Neutral Atmospheric Form Drag Coefficient From Surface Features, $C_{d a, f r^{\prime}}^{n}$ and the Total Neutral Atmospheric Drag Coefficient, $C_{\mathrm{da}, \mathrm{fr}}^{n}$ (equation (7)), Using the ASCAT Extrapolation of the IceBridge Drag Results, Averaged Over the Central Arctic (CA), Beaufort/Chukchi (BC), and Arctic Ocean (AO) Regions ${ }^{\mathrm{a}}$

\begin{tabular}{|c|c|c|c|c|c|c|}
\hline \multirow[b]{2}{*}{ Year } & \multicolumn{3}{|c|}{$C_{\mathrm{da}, \mathrm{fr}}^{n}\left(10^{-3}\right)$} & \multicolumn{3}{|c|}{$C_{\mathrm{da}}^{n}\left(10^{-3}\right)$} \\
\hline & $C A$ & $B C$ & $\mathrm{AO}$ & $C A$ & $B C$ & $\mathrm{AO}$ \\
\hline 2009 & $0.52(0.22)$ & $0.29(0.13)$ & $0.32(0.17)$ & $1.33(0.21)$ & $1.15(0.17)$ & $1.19(0.19)$ \\
\hline 2010 & $0.60(0.16)$ & $0.31(0.14)$ & $0.34(0.17)$ & $1.42(0.15)$ & $1.19(0.16)$ & $1.20(0.19)$ \\
\hline 2011 & $0.52(0.18)$ & $0.30(0.13)$ & $0.32(0.16)$ & $1.34(0.17)$ & $1.18(0.16)$ & $1.20(0.18)$ \\
\hline 2012 & $0.53(0.18)$ & $0.25(0.11)$ & $0.30(0.16)$ & $1.35(0.16)$ & $1.09(0.15)$ & $1.17(0.20)$ \\
\hline 2013 & $0.53(0.19)$ & $0.26(0.09)$ & $0.28(0.16)$ & $1.35(0.19)$ & $1.12(0.14)$ & $1.16(0.18)$ \\
\hline 2014 & $0.66(0.26)$ & $0.36(0.16)$ & $0.36(0.23)$ & $1.50(0.22)$ & $1.24(0.17)$ & $1.25(0.24)$ \\
\hline 2015 & $0.70(0.32)$ & $0.41(0.21)$ & $0.36(0.27)$ & $1.51(0.31)$ & $1.28(0.20)$ & $1.24(0.27)$ \\
\hline
\end{tabular}

Our annual estimates of the total neutral atmospheric drag over Arctic sea ice in spring, from 2009 to 2015 , using equation (7) are given in Figure 12.

The maps graphically demonstrate the variability in the neutral drag coefficient, $C_{d a}^{n}$, due to the various sea ice/open water conditions. The smooth, first-year ice that dominates the eastern Arctic and parts of the western Arctic (Beaufort/Chukchi Seas) features the lowest values of $C_{\mathrm{da}}^{n}\left(\sim 1 \times 10^{-3}\right)$ driven primarily by the contribution from skin drag, $C_{\mathrm{da}, \mathrm{s}}^{n}\left(0.8 \times 10^{-3}\right)$. In the $\mathrm{MIZ}$, we see a strong (but limited areal coverage) increase in $C_{\mathrm{da}}^{n}\left(\sim 2-2.5 \times 10^{-3}\right)$, due to the form drag from floe edges, $C_{\mathrm{da}, \mathrm{ff}}^{n}$. The deformed, multiyear ice north of Greenland and the Canadian Archipelago features $C_{d a}^{n}$ values broadly similar to those expected over the open ocean $\left(\sim 1.5 \times 10^{-3}\right)$, but in 2015 especially, we estimate values closer to those expected in the MIZ $\left(\sim 2.0 \times 10^{-3}\right)$. The results suggest that while the MIZ form drag component, $C_{d a, f f^{\prime}}^{n}$ is significant, the arguably overlooked drag contribution from surface feature variability, $C_{\mathrm{da}, \mathrm{fr}}^{n}$, may be as significant and should not be overlooked when estimating the total neutral atmospheric drag coefficient over Arctic sea ice. Again, it is worth noting that these drag coefficient estimates are for the early spring time period. In late spring and summer, when the MIZ and melt pond coverage increases, the contribution to form drag from floe and melt pond edges is thought to become more significant [e.g., Lüpkes et al., 2013; Tsamados et al., 2014].

The interannual variability of $C_{\mathrm{da} \text {,fr }}^{n}$ and $C_{\mathrm{da}}^{n}$ using the ASCAT extrapolated data within the CA, BC, and Arctic Ocean (AO) regions are given in Table 2. The use of the ASCAT data help avoid the spatial biasing issues present in the annual OIB data sets, which are caused by annual changes in the OIB sea ice campaign flight lines, including the general tendency of the OIB lines to profile closer to the coastline of the CA region. Note that the $A O$ study region broadly neglects the $\mathrm{MIZ}$ (see the $\mathrm{AO}$ region mask in Figures 11 and 12 ) and thus mainly involves the addition of the skin drag term $\left(C_{d a, s}^{n}=0.8 \times 10^{-3}\right)$. Table 2 shows that the ASCAT/OIB AO form drag coefficient is now highest in $2014 / 2015\left(C_{\mathrm{da}}^{n}=1.25 \pm 0.24 \times 10^{-3} / 1.24 \pm 0.24 \times 10^{-3}\right)$, compared to previous years (e.g., $C_{\mathrm{da}}^{n}=1.19 \pm 0.19 \times 10^{-3}$ in 2009) with the $C A$ and $B C$ regions showing a broadly similar pattern of interannual variability.

\section{Summary}

In this study we presented new estimates of the neutral atmospheric form drag coefficient over Arctic sea ice due to surface feature variability, $C_{d a}^{n}$, fr . We utilized surface feature data produced by Petty et al. [2016] from the Airborne Topographic Mapper (ATM) laser altimeter, flown on board NASA's Operation IceBridge (OIB) mission. We combined the surface feature height data with a new metric of feature spacing to produce estimates of $C_{\mathrm{da} \text {, fr }}^{n}$ using an existing form drag parameterization scheme. To be consistent with previous studies investigating form drag and to help validate the results from this new full scan topography data set, we compared these estimates with those produced using linear profiling (a new OIB topography data set). 


\section{Acknowledgments}

This work was supported by the NASA Operation IceBridge Project Science Office, NASA grant NNX13AK36G. We acknowledge and sincerely appreciate the efforts of the various IceBridge team members who contributed to the collection, processing, and archiving of the various data sets utilized in this study. NASA's Operation IceBridge (OIB) Airborne Topographic Mapper (ATM) data are available at https://nsidc.org/data/ilatm1b/ (regular, wide swath). The IceBridge Digital Mapping System (DMS) images are available at http://nsidc.org/data/ iodms 1b. Advanced Scatterometer (ASCAT) radar backscatter data (quasi-daily, SIR data at $4.45 \mathrm{~km}$ resolution covering all 2009-2015 OIB sea ice campaigns) were obtained from the NASA sponsored Scatterometer Climate Record Pathfinder at Brigham Young University (http://www.scp.byu.edu/). We thank David Long for his assistance regarding the acquisition and analysis of all ASCAT/SIR data. The daily NASA Team ice concentration data (2009-2015 spring data are used in this study) are made available at (http://nsidc.org/data/nsidc-0051) by the National Snow and Ice Data Center (NSIDC). The derived Arctic OIB ice topography data (2009-2014) have been archived at https://zenodo.org/record/51569, and all processing scripts used to generate these data are available at http://www.github.com/akpetty/ ibtopo2016.git or by contacting the primary author directly. The new processing scripts used in this study are available at http://www. github.com/akpetty/ibdrag2017.git. The 2009-2015 ice topography and form drag data will also be archived at NASA's Cryospheric Sciences Lab website (http://cryosphere.gsfc.nasa.gov) We thank the reviewers and Editor for their assistance in evaluating the manuscript, and for Christian Haas for discussions related to the ASCAT analysis.
Our estimates of $C_{\mathrm{da} \text {, fr }}^{n}$ exhibit strong regional variability, including low values $\left(C_{\mathrm{da}, \mathrm{fr}}^{n}<0.5-1 \times 10^{-3}\right)$ over the smoother, first-year ice, of the Beaufort/Chukchi Seas, compared with higher values $\left(C_{\mathrm{da}, \mathrm{fr}}^{n}>0.5-1 \times 10^{-3}\right)$ over the deformed, multiyear ice of the Central Arctic (north of Greenland and the Canadian Archipelago). $C_{\mathrm{da} \text {, fr }}^{n}$ within the Central Arctic increases monotonically with increasing coastline proximity (shown using box and whisker plots). $C_{d a, f r}^{n}$ also exhibits moderate interannual variability, including a strong increase from 2013 to 2015 across the more deformed ice north of the Canadian Archipelago.

We find that the surface feature heights (spacings) are smaller (larger) in the linear profiling method, which broadly compensate to produce similar estimates of $C_{\mathrm{da} \text {, fr }}^{n}$ (the full scan results are roughly $10-20 \%$ lower than the linear profiling estimates). The $C_{\mathrm{da} \text {, fr }}^{n}$ results are within the range of values demonstrated in previous studies, although our ability to validate these estimates, including the differences between the two topography data sets, are hindered by the lack of coincident form drag estimates/turbulent flux measurements within the consolidated ice pack.

The full scan OIB $C_{\mathrm{da} \text {, fr }}^{n}$ estimates showed strong correlation with ASCAT radar backscatter data, and we used the regressions to extrapolate our OIB $C_{\mathrm{da} \text {, fr }}^{n}$ results across the Arctic Ocean (within the consolidated ice pack). The ASCAT/OIB $C_{d a, f r}^{n}$ results were combined with existing parameterizations of form drag from floe edges (a function of ice concentration), skin drag over level ice, and the total drag over open water, to produce a pan-Arctic estimate of the total neutral atmospheric drag, $C_{\mathrm{da}}^{n}$ in early spring from 2009 to 2015.

In future work we hope to explore the production of ice topography and form drag estimates using the arguably underused Southern Ocean OIB sea ice data. We also hope to use these observational estimates of form drag coefficients to calibrate the Tsamados et al. [2014] form drag scheme in CICE and explore, in detail, the physical impact of the variable atmospheric (and oceanic) form drag coefficient on the sea ice mass balance.

\section{References}

Aaboe, S., L.-A. Breivik, A. Sørensen, S. Eastwood, and T. Lavergne (2015), Global sea ice edge and type product user's manual, Product OSI-403-b, EUMETSAT Ocean and Sea Ice Satellite Application Facility. [Available at http://saf.met.no/docs/osisaf_cdop2_ss2_pum_ ice-edge-type_v1p1.pdf.]

Andreas, E. L., T. W. Horst, A. A. Grachev, P. O. G. Persson, C. W. Fairall, P. S. Guest, and R. E. Jordan (2010), Parametrizing turbulent exchange over summer sea ice and the marginal ice zone, Q. J. R. Meteorol. Soc., 136(649), 927-943, doi:10.1002/qj.618.

Andreas, E. L., L. Mahrt, and D. Vickers (2012), A new drag relation for aerodynamically rough flow over the ocean, J. Atmos. Sci., 69(8), 2520-2537, doi:10.1175/JAS-D-11-0312.1.

Arya, S. P. S. (1973), Contribution of form drag on pressure ridges to the air stress on Arctic ice, J. Geophys. Res., 78(30), 7092-7099, doi:10.1029/JC078i030p07092.

Arya, S. P. S. (1975), A drag partition theory for determining the large-scale roughness parameter and wind stress on the Arctic pack ice, J. Geophys. Res., 80(24), 3447-3454, doi:10.1029/JC080i024p03447.

Beckers, J. F., A. H. H. Renner, G. Spreen, S. Gerland, and C. Haas (2015), Sea-ice surface roughness estimates from airborne laser scanner and laser altimeter observations in Fram Strait and north of Svalbard, Ann. Glaciol., 56(69), 235-244, doi:10.3189/2015AoG69A717.

Birnbaum, G., and C. Lupkes (2002), A new parameterization of surface drag in the marginal sea ice zone, Tellus A, 54(1), 107-123, doi:10.1034/j.1600-0870.2002.00243.x.

Breivik, L. A., and S. Eastwood (2009), Upgrade of the OSI SAF sea ice edge and sea ice type products - Introduction of ASCAT, OSI SAF Report.

Brown, R. A. (1980), Planetary boundary layer modeling for AIDJEX, in Sea Ice Process and Model, edited by R. S. Pritchard, pp. 387-401, Univ. of Wash. Press, Seattle.

Castellani, G., C. Lüpkes, S. Hendricks, and R. Gerdes (2014), Variability of Arctic sea-ice topography and its impact on the atmospheric surface drag, J. Geophys. Res. Oceans, 119(10), 6743-6762, doi:10.1002/2013JC009712.

Cavalieri, D., C. Parkinson, P. Gloersen, and Jay. H Zwally (1996), Sea Ice Concentrations From Nimbus-7 SMMR and DMSP SSM/I-SSMIS Passive Microwave Data, Version 1, NASA DAAC at the Natl. Snow and Ice Data Cent., Boulder, Colo.

Dierking, W. (1995), Laser profiling of the ice surface topography during the Winter Weddell Gyre Study 1992, J. Geophys. Res., 100(C3), 4807-4820, doi:10.1029/94JC01938.

Dominguez, R. (2010), IceBridge DMS L1B Geolocated and Orthorectified Images, Version 1, NASA DAAC the National Snow and Ice Data Center, Boulder, Colo.

Elvidge, A. D., I. A. Renfrew, A. I. Weiss, I. M. Brooks, T. A. Lachlan-Cope, and J. C. King (2016), Observations of surface momentum exchange over the marginal ice zone and recommendations for its parametrisation, Atmos. Chem. Phys., 16(3), 1545-1563, doi:10.5194/acp-16-1545-2016.

Garbrecht, T., C. Lüpkes, J. Hartmann, and M. Wolff (2002), Atmospheric drag coefficients over sea ice - Validation of a parameterisation concept, Tellus A, 54(2), 205-219, doi:10.1034/j.1600-0870.2002.01253.x.

Guest, P. S., and K. L. Davidson (1991), The aerodynamic roughness of different types of sea ice, J. Geophys. Res., 96(C3), 4709-4721, doi:10.1029/90JC02261.

Hanssen-Bauer, I., and Y. T. Gjessing (1988), Observations and model calculations of aerodynamic drag on sea ice in the Fram Strait, Tellus $A$, 40A(2), 151-161, doi:10.1111/j.1600-0870.1988.tb00413.x.

Hibler, W. D. I., W. F. Weeks, and S. Mock (1972), Statistical aspects of sea ice ridge distributions, J. Geophys. Res., 77, 5954-5970, doi:10.1029/JC077i030p05954. 
Hibler III, W. D. (1979), A dynamic thermodynamic sea ice model, J. Phys. Oceanogr., 9(4), 815-846, doi:10.1175/1520-0485(1979)009<0815:ADTSIM>2.0.CO;2.

Krabill, W. (2013), IceBridge ATM L1B Elevation and Return Strength, Version 2 [2009-2015], NASA DAAC at the National Snow and Ice Data Center, Boulder, Colo.

Kwok, R. (2015), Sea ice convergence along the Arctic coasts of Greenland and the Canadian Arctic Archipelago: Variability and extremes (1992-2014), Geophys. Res. Lett., 42, 7598-7605, doi:10.1002/2015GL065462.

Lensu, M. (2003), The evolution of ridged ice fields, PhD thesis, Dep. of Mech. Eng., Helsinki Univ. of Technol., Helsinki, Finland.

Leonardi, S., P. Orlandi, R. J. Smalley, L. Djenidi, and R. A. Antonia (2003), Direct numerical simulations of turbulent channel flow with transverse square bars on one wall, J. Fluid Mech., 491, 229-238, doi:10.1017/S0022112003005500.

Lewis, J. E. (1993), Statistical properties of sea ice surface topography in the Baltic Sea, Tellus A, 45(2), 127-142, doi:10.1034/j.1600-0870.1993.t01-1-00004.x.

Lindell, D. B., and D. G. Long (2016), Multiyear Arctic ice classification using ASCAT and SSMIS, Remote Sens., 8(4), 294, doi:10.3390/rs8040294.

Lindsley, R. D., and D. G. Long (2016), Enhanced-resolution reconstruction of ASCAT backscatter measurements, IEEE Trans. Geosci. Remote Sens., 54(5), 2589-2601, doi:10.1109/TGRS.2015.2503762.

Lüpkes, C., and G. Birnbaum (2005), Surface drag in the arctic marginal sea-ice zone: A comparison of different parameterisation concepts, Boundary Layer Meteorol., 117(2), 179-211, doi:10.1007/s10546-005-1445-8.

Lüpkes, C., V. M. Gryanik, J. Hartmann, and E. L. Andreas (2012), A parametrization, based on sea ice morphology, of the neutral atmospheric drag coefficients for weather prediction and climate models, J. Geophys. Res., 117, D13112, doi:10.1029/2012JD017630.

Lüpkes, C., V. M. Gryanik, A. Rösel, G. Birnbaum, and L. Kaleschke (2013), Effect of sea ice morphology during Arctic summer on atmospheric drag coefficients used in climate models, Geophys. Res. Lett., 40, 446-451, doi:10.1002/grl.50081.

Mai, S., C. Wamser, and C. Kottmeier (1996), Geometric and aerodynamic roughness of sea ice, Boundary Layer Meteorol., 77(3-4), 233-248, doi:10.1007/BF00123526.

Martin, T. (2007), Arctic sea ice dynamics: Drift and ridging in numerical models and observations, PhD thesis, Alfred Wegener Inst. for Polar and Marine Res., Univ. of Bremen, Bremerhaven, Germany.

Martin, T., M. Tsamados, D. Schroeder, and D. L. Feltham (2016), The impact of variable sea ice roughness on changes in Arctic Ocean surface stress: A model study, J. Geophys. Res. Oceans, 121, 1931-1952, doi:10.1002/2015JC011186.

Maslanik, J., J. Stroeve, C. Fowler, and W. Emery (2011), Distribution and trends in Arctic sea ice age through spring 2011, Geophys. Res. Lett., 38, L13502, doi:10.1029/2011GL047735.

Mock, S. J., A. D. Hartwell, and W. D. Hibler III (1972), Spatial aspects of pressure ridge statistics, J. Geophys. Res., 77(30), 5945-5953, doi:10.1029/JC077i030p05945.

Mortin, J., S. E. L. Howell, L. Wang, C. Derksen, G. Svensson, R. G. Graversen, and T. M. Schrøder (2014), Extending the QuikSCAT record of seasonal melt —Freeze transitions over Arctic sea ice using ASCAT, Remote Sens. Environ., 141, 214-230, doi:10.1016/j.rse.2013.11.004.

Nghiem, S. V., R. Kwok, S. H. Yueh, and M. R. Drinkwater (1995), Polarimetric signatures of sea ice: 2. Experimental observations, J. Geophys. Res., 100(C7), 13,681-13,698, doi:10.1029/95JC00938.

Overland, J. E. (1985), Atmospheric boundary layer structure and drag coefficients over sea ice, J. Geophys. Res., 90(C5), 9029-9049, doi:10.1029/JC090iC05p09029.

Petty, A. A., M. C. Tsamados, N. T. Kurtz, S. L. Farrell, T. Newman, J. P. Harbeck, D. L. Feltham, and J. A. Richter-Menge (2016), Characterizing Arctic sea ice topography using high-resolution IceBridge data, The Cryosphere, 10(3), 1161-1179, doi:10.5194/tc-10-1161-2016.

Rivas, M. B., J. Verspeek, A. Verhoef, and A. Stoffelen (2012), Bayesian sea ice detection with the advanced scatterometer ASCAT, IEEE Trans. Geosci. Remote Sens., 50(7), 2649-2657, doi:10.1109/TGRS.2011.2182356.

Schröder, D., T. Vihma, A. Kerber, and B. Brümmer (2003), On the parameterization of turbulent surface fluxes over heterogeneous sea ice surfaces, J. Geophys. Res., 108(C6), 3195, doi:10.1029/2002JC001385.

Steele, M., J. Zhang, D. Rothrock, and H. Stern (1997), The force balance of sea ice in a numerical model of the Arctic Ocean, J. Geophys. Res., 102(C9), 21,061-21,079, doi:10.1029/97JC01454.

Tan, B., Z. Li, P. Lu, C. Haas, and M. Nicolaus (2012), Morphology of sea ice pressure ridges in the northwestern Weddell Sea in winter, J. Geophys. Res., 117, C06024, doi:10.1029/2011JC007800.

Thorndike, A. S., and R. Colony (1982), Sea ice motion in response to geostrophic winds, J. Geophys. Res., 87(C8), 5845-5852, doi:10.1029/JC087iC08p05845.

Tsamados, M., D. L. Feltham, D. Schroeder, D. Flocco, S. L. Farrell, N. Kurtz, S. W. Laxon, and S. Bacon (2014), Impact of variable atmospheric and oceanic form drag on simulations of Arctic sea ice, J. Phys. Oceanogr., 44, 1329-1353, doi:10.1175/JPO-D-13-0215.1.

Tsamados, M., D. Feltham, A. Petty, D. Schroeder, and D. Flocco (2015), Processes controlling surface, bottom and lateral melt of Arctic sea ice in a state of the art sea ice model, Phil. Trans. R. Soc. A, 373, 2052, doi:10.1098/rsta.2014.0167.

Tucker, W. B., W. F. Weeks, and M. Frank (1979), Sea ice ridging over the Alaskan Continental Shelf, J. Geophys. Res., 84(C8), 4885-4897, doi:10.1029/JC084iC08p04885.

Wadhams, P., and T. Davy (1986), On the spacing and draft distributions for pressure ridge keels, J. Geophys. Res., 91(C9), 10,697-10,708, doi:10.1029/JC091iC09p10697.

Wadhams, P., and R. J. Horne (1980), An analysis of ice profiles obtained by submarine sonar in the Beaufort Sea, J. Glaciol., $25,401-424$.

Webster, M. A., I. G. Rigor, S. V. Nghiem, N. T. Kurtz, S. L. Farrell, D. K. Perovich, and M. Sturm (2014), Interdecadal changes in snow depth on Arctic sea ice, J. Geophys. Res. Oceans, 119, 5395-5406, doi:10.1002/2014JC009985.

Wittmann, W., and J. Schule (1966), Comments on the mass budget of arctic pack ice, in Proceedings of the Symposium on the Arctic Heat Budget and Atmospheric Circulation, edited by J. O. Fletcher, pp. 215-246, Rand Co., Santa Monica, Calif.

Zhang, J., and D. A. Rothrock (2003), Modeling global sea ice with a thickness and enthalpy distribution model in generalized curvilinear coordinates, Mon. Weather Rev., 131(5), 845-861, doi:10.1175/1520-0493(2003)131<0845:MGSIWA>2.0.CO;2. 